\title{
Desafios da carcinicultura: aspectos legais, impactos ambientais e alternativas mitigadoras *
}

\author{
Challenges of shrimp farming: legal aspects, environmental impacts \\ and mitigating alternatives
}

\author{
Luisa Ferreira Ribeiro ${ }^{\circledR, 1,2,3}$; Manuel Macedo de Souza ${ }^{1,3}$; Francisco Barros ${ }^{2,3}$; Vanessa Hatje ${ }^{1,3}$
}

\begin{abstract}
RESUMO
A aquicultura pode ser definida como o cultivo de organismos aquáticos em água marinha, salobra ou doce. Entre as diversas atividades que compõem a aquicultura, a carcinicultura destaca-se por sua ampla difusão em várias partes do mundo. Este artigo tem como objetivo fazer uma revisão sobre a carcinicultura e os aspectos legais que controlam tal atividade, bem como relatar os principais impactos ambientais gerados e as ações mitigadoras atualmente utilizadas no Brasil. Com o aumento do número de empreendimentos, houve a necessidade de regulamentar essa atividade, no entanto, em muitos países, tal regulamentação não ocorreu de forma específica. Consequentemente, a carcinicultura vem sendo, em muitos casos, regulada por códigos e leis adaptados de outros já vigentes. Apesar dos índices econômicos positivos divulgados pelos produtores e órgãos governamentais, essa atividade é frequentemente associada a efeitos adversos nos ecossistemas adjacentes, causados por efluentes liberados pelas fazendas de camarão, pela destruição de áreas de manguezais e pela salinização de corpos d'água, entre outros motivos. Problemas socioeconômicos que afetam as comunidades de pescadores artesanais também têm sido frequentemente associados às atividades de carcinicultura. Muitas das alternativas propostas para mitigar os problemas gerados por essa atividade apresentam um elevado valor para implantação, dificultando sua incorporação nas fazendas. Uma análise da literatura indica que é possível tornar a carcinicultura rentável ao mesmo tempo em que sustentável, por meio da implementação de medidas mitigadoras e da aplicação das leis e diretrizes existentes.
\end{abstract}

Palavras-chave: carcinicultura, legislação, impactos ambientais, alternativas mitigadoras.

\begin{abstract}
Among the various activities that are included in the aquaculture, shrimp farming stands out for its wide dissemination in various parts of the world. It is clear that, for decades, the global production and financial performance by shrimp farming achieved excellent results. However, it is also well accepted that the rapid and often uncontrolled growth of this activity frequently results in several environmental, economic and social problems. Thus, critical reviews on this activity are needed. This paper aims to contextualize the Brazilian shrimp in the world market, make a brief review on the functioning of shrimp farms, compare and discuss some important legal aspects and report and discuss the main environmental impacts and mitigation actions. The favorable environmental conditions and new technologies motivated the shrimp production and led Brazil to be one of the largest shrimp producers in the word. The rapid development and the globally increasing number of shrimp farm initiatives demanded regulation of the aquaculture activities. In many countries, including Brazil, this regulation did not occur specifically for the shrimp farming. As a result, the shrimp farming is currently regulated by numerous codes and laws adapted from others related activities. Moreover, states, municipalities and districts can each develop and apply
\end{abstract}

\footnotetext{
@ Corresponding author: <luisa_bio@hotmail.com>

${ }^{1}$ Universidade Federal da Bahia (UFBA), Instituto de Química, Departamento de Química Analítica, Campus Ondina, Salvador, BA 40170290, Brasil.

${ }^{2}$ Universidade Federal da Bahia (UFBA), Instituto de Biologia, Departamento de Zoologia, Campus Ondina, Salvador, BA 40170-290, Brasil.

${ }^{3}$ Universidade Federal da Bahia (UFBA), INCT de Ambientes Marinhos Tropicais, 40170-290, Salvador, BA, Brasil.
} 
specific regulations to control the aquaculture. As a result, there is an overlap of the governmental actions and policies that makes shrimp farming regulation a very complex and confusing, and consequently, very difficult to be applied. Despite the frequent positive economic indicators obtained by the producers, shrimp farming activity still is frequently associated with serious negative social and environmental impacts. The magnitude, frequency and duration of these impacts can be related to many factors, mostly farm and pound location, nurseries type and management, production size and types, technology employed and hydrodynamics of adjacent water bodies. Negative impacts, including ecological instability, environmental contamination, disease outbreaks, among others, are often due to lack of adequate development planning worldwide, and Brazil is no exception. Furthermore, the environmental and social impacts are associated not only with the installation but also with the operation of shrimp farms. Several studies suggested that the negative social impacts associated with aquaculture deserve higher attention. For instance, some studies suggested that shrimp farming promote marginalization and migration of traditional communities and unemployment. Moreover, it can also encourage the rupture of the traditional ways of shellfish harvesting (gathering) and fisheries practices, causing social conflicts. Among the reported environmental problems, loss of mangrove ecological services and other coastal areas, during the construction and operation of farms, and the abandonment of these farmed areas are suggested among the most important impacts, affecting the environment and the economy of traditional communities. Effluent releases by farms can also have a significant impact in the nearby natural systems (e.g. estuaries). These effluents are generally rich in nutrients, causing eutrophication of water bodies and sporadic toxic algae blooms. The liquid residues of shrimp farming can be loaded with inorganic elements, such as toxic metals, including mercury. Antibiotics and antimicrobial agents might also be presented in effluents once they are widely used to promote biomass grow, better assimilation of food and treatment of diseases. However, the effects of antibiotics and antimicrobial agents in the receiving ecosystems are still poorly studied. There is a demand for high profitability and rapid growth of shrimp farming activities in Brazil. The negative impacts of this activity together with the inefficiency of the regulating agencies may cause several socio-economic and environmental problems. Nevertheless, there are several mitigating alternatives for the negative impacts associated with shrimp farming. Most of them are associated with high costs procedures, frequently hampering their adoption. Bioremediation, for instance, has been pointed out as the best alternative to the treatment of waters subject to high loads of organic contaminants. The recirculating water system (RAS) can remove most of the contaminants in the water. For the manure and feeding it has been suggested the use of specific arrangement of the feeders along the tanks, as a strategy to limit the amount of fertilizer to be applied. To address the problems related to the use of antibiotics and antimicrobials the recommendation is the use of medicated feed. However, none of these aforementioned techniques is efficient without the adoption of the best management practices. The shrimp farming can be profitable while sustainable through the implementation of mitigating alternatives and following good practices that preserves environment and respect traditional communities.

Keywords: shrimp farming, legislation, impacts, mitigating alternatives.

\section{Introdução}

A aquicultura pode ser definida como o cultivo de organismos (animais e plantas) que têm na água marinha, salobra ou doce o seu principal habitat (Camargo \& Pouey, 2005; Pillay \& Kutty, 2005), abrangendo, dessa maneira, organismos estritamente aquáticos e anfíbios. Dentre os diversos ramos da aquicultura, os mais praticados são a criação de ostras (ostreicultura), peixes (piscicultura), rãs (ranicultura) e camarões (carcinicultura) (Pullin et al., 1993).

Nas últimas décadas, a aquicultura apresentou uma rápida expansão e hoje contribui com $43 \%$ de toda a proteína animal de origem aquática consumida pelo homem, chegando a cerca de 68 milhões de toneladas da oferta mundial de pescado (Bostock et al., 2010). O rápido crescimento dessa atividade está associado a inúmeros fatores, destacando-se o desenvolvimento técnico-científico e o declínio mundial dos estoques pesqueiros naturais, devido, principalmente, à sobrepesca (Camargo \& Pouey, 2005; Naylor et al., 2005; FAO, 2006).

Em termos globais, a produção e o desempenho financeiro da carcinicultura alcançaram resultados excelentes por um longo período de tempo. Entretanto, o rápido e, muitas vezes, desordenado crescimento dessa atividade gerou uma série de problemas ambientais, econômicos e sociais. Dentre esses, podemos destacar a disseminação de doenças entre os camarões cultivados, desmatamento de manguezais para implantação dos tanques, redução da fertilidade do solo dos viveiros, contaminação das águas e dos sedimentos, salinização de aquíferos, introdução de espécies exóticas, deslocamento e migração de comunidades tradicionais, deterioração da qualidade de vida e da segurança alimentar de comunidades tradicionais, entre outros (e.g., Alam et al., 2005; Meirelles, 2005; Primavera, 2006; Meireles \& Queiroz, 2010; Paul \& Vogl, 2011; Lacerda et al., 2011; Nomen et al., 2012; Nóbrega et al., 2013).

Diversas soluções têm sido propostas para mitigar os impactos gerados pelas atividades de carcinicultura, seja para reduzir os efeitos negativos no ambiente ou para garantir a rentabilidade da atividade (Smith et al., 2002). Essas soluções não se restringem aos aspectos técnicos, mas também aos aspectos legais, como a criação de normas e legislações visando regulamentar a carcinicultura e, potencialmente, minimizar a geração de impactos socioambientais e/ou econômicos negativos. 
O presente artigo tem como objetivo fazer uma revisão sobre a atividade de carcinicultura no Brasil e os aspectos legais que controlam tal atividade, bem como relatar os principais impactos gerados, principalmente na esfera ambiental, e as ações mitigadoras atualmente praticadas.

\section{A carcinicultura brasileira no mercado mundial}

No Brasil, o clima favorável e o domínio de novas tecnologias de produção de camarões favoreceram o estabelecimento do país como um dos principais produtores de camarão das Américas (Poersch, 2004). Entre 2002 e 2003, por exemplo, houve um aumento da produção em $50 \%$, atingindo 90.190 toneladas e uma produtividade média de 6 ton/ha/ano, considerada a maior taxa entre todos os países produtores (Rocha et al., 2004). Após 2003, a carcinicultura vivenciou um decréscimo devido a infecções causadas pelo vírus da Mionecrose infecciosa (IMNV), que rapidamente se espalhou pelo nordeste do país (Natori et al., 2011). Atualmente, o Brasil ocupa o sexto lugar na lista mundial de produtores, tendo como principais consumidores a França, o Japão e a Espanha, que juntos importam 96\% do que é produzido no país (MPA, 2011). O mercado interno, por sua vez, passou por uma grande transformação, pois era desconhecido e explorado apenas por um grupo pequeno de produtores (Bezerra, 2010).

Entre as regiões brasileiras, a Nordeste é a que mais se destaca nas atividades de carcinicultura, sendo responsável por $94 \%$ do total da produção, especialmente os estados do Rio Grande do Norte e da Bahia, além do Ceará, da Paraíba, de Pernambuco e do Piauí, onde a atividade se apresenta em expansão (ABCC, 2005). Essa disparidade em relação aos outros estados da federação está associada, entre outros fatores, à extensa faixa litorânea nordestina e às condições climatológicas, hidrológicas e topográficas ideais para o cultivo do camarão (Quaglia, 1993; Castro \& Pagani, 2004).

Além de ótimas condições ambientais para a carcinicultura, a região Nordeste foi pioneira em estudos técnicos que visaram à implantação e ao desenvolvimento da atividade no país. No início da década de 1970, foram realizados testes de produção com diferentes espécies do gênero Penaeus, nos quais ficou evidenciado que o Penaeus vannamei era a melhor espécie para ser cultivada devido à sua alta adaptabilidade, rapidez no crescimento, ampla faixa de tolerância à salinidade, entre outras razões (Costa, 2004). Por se tratar de uma espécie exótica, seu cultivo teve um início bastante controverso. O sucesso dos empreendimentos que utilizaram o $P$. vannamei, entretanto, favoreceu e incentivou o uso da espécie no país (Moles \& Bunge, 2002). O crescimento e os bons resultados obtidos com o $P$. vannamei foram subsidiados por vários fatores, incluindo o incentivo a uma incubadora no Rio Grande do Norte, a estabilização econômica do país, a colaboração técnica de universidades, incentivos governamentais, financiamento bancário e a permissividade legislativa (Queiroz et al., 2013). No ano de 1999, com a queda da produção de camarão em países do Pacífico, a elevação do preço do camarão no mercado internacional e a desvalorização do real, a atividade começou a obter grandes lucros e, consequentemente, a atrair investimentos de empreendedores nacionais e internacionais (IBAMA, 2005; MPA, 2011).

\section{Funcionamento das fazendas de camarões}

Diversos tipos de sistemas de cultivo de camarões são utilizados no mundo, tais como viveiros escavados em terra, tanques à base de concreto, gaiolas flutuantes e cercados. Os cultivos também se diferenciam na forma de alimentação, bem como nas taxas de renovação de água, as quais têm consequência na quantidade e qualidade dos efluentes gerados.

Os sistemas de cultivo de camarões em cativeiro podem ser divididos em quatro etapas principais: larvicultura, berçário, engorda e despesca (Tabela 1). Devido às necessidades singulares de cada estágio de vida do camarão, muitas vezes, as diferentes etapas são realizadas em tanques ou em localidades diferentes. Baseada nesse aspecto, a carcinicultura pode ser classificada em mono, bi ou trifásica. Nos cultivos monofásicos, todas as etapas ocorrem no mesmo tanque e, muitas vezes, as pós-larvas são capturadas no ambiente. Já o cultivo bifásico é composto pela fase de berçário e de engorda, e as pós-larvas são compradas em empresas especializadas. No Brasil, grande parte dos empreendimentos adota este sistema, pois a fase de larvicultura é considerada a mais cara e somente é necessária no início do ciclo de cultivo. O sistema trifásico é composto pelas etapas de larvicultura, berçário e engorda, sendo encontrado, principalmente, em grandes empreendimentos de carcinicultura (Kungvankij et al., 1989; Azevêdo, 2005).

Com relação à intensidade dos sistemas de cultivo, a carcinicultura pode ser classificada em extensiva, semi intensiva, intensiva e hiper-intensiva (Tabela 2). O sistema semi-intensivo é o que possui retorno financeiro mais rápido e o que necessita de, relativamente, menor investimento para sua implantação (Nunes, 2001). Com relação ao custo de manutenção, o semi-intensivo é mais oneroso que o extensivo, porém mais barato quando comparado com o intensivo e o hiper-intensivo (Burford et al., 2003). Os elevados custos dos sistemas intensivo e hiper-intensivo estão associados, principalmente, à utilização de altas quantidades de rações balanceadas (Tabela 2) e à necessidade de areação artificial, gerenciamento da qualidade da água e, em alguns casos, antibióticos (Barros, 2006; Mamani, 2007). 
Tabela 1. Etapas da cadeia produtiva do camarão.

Table 1. Stages of the shrimp productive chain.

\begin{tabular}{|c|c|c|c|}
\hline Etapas & \multicolumn{2}{|l|}{ Descrição } & Alimentação \\
\hline Larvicultura & \multicolumn{2}{|c|}{$\begin{array}{l}\text { Produção de larvas. Após período de adaptação é } \\
\text { realizado uma seleção onde os mais aptos são } \\
\text { escolhidos e os organismos selecionados são } \\
\text { transferidos para os tanques berçários }\end{array}$} & $\begin{array}{l}\text { Organismos vivos, náuplius de artemia. Na etapa de } \\
\text { pós-larva, a alimentação é baseada em ração } \\
\text { balanceada apresentando entre } 35 \text { e } 45 \% \text { de proteína. }\end{array}$ \\
\hline Berçário & \multicolumn{2}{|c|}{$\begin{array}{l}\text { Aclimatação às condições ambientais da fazenda } \\
\text { e seleção dos indivíduos mais resistentes e com } \\
\text { tamanho homogêneo para a fase de engorda }\end{array}$} & $\begin{array}{l}\text { A alimentação é similar a das pós-larvas, com } \\
\text { diferença na quantidade de ração balanceada. Além } \\
\text { disso, existe a contribuição da alimentação natural, } \\
\text { auxiliada pela fertilização orgânica e inorgânica das } \\
\text { águas dos tanques. }\end{array}$ \\
\hline Engorda & \multicolumn{2}{|c|}{$\begin{array}{l}\text { Os viveiros recebem maior quantidade de ração } \\
\text { com o intuito de que os animais cultivados } \\
\text { alcancem tamanho e peso ideais para despesca }\end{array}$} & $\begin{array}{l}\text { Durante esta etapa a quantidade de ração é } \\
\text { proporcional à biomassa total de camarões no tanque. } \\
\text { Desta forma, a quantidade de ração diminui, mas o } \\
\text { percentual de proteína aumenta. }\end{array}$ \\
\hline Despesca & \multicolumn{3}{|c|}{$\begin{array}{l}\text { Retirada da água dos tanques, coleta e abate dos } \\
\text { camarões }\end{array}$} \\
\hline \multicolumn{4}{|c|}{$\begin{array}{l}\text { Adaptado de Kungvankij et al., (1989), Nunes (2004) } \\
\text { Adpated from Kungvankij et al. (1989), Nunes, (2004) }\end{array}$} \\
\hline \multirow{2}{*}{\multicolumn{4}{|c|}{$\begin{array}{l}\text { Tabela } 2 \text { - Características dos tipos de cultivo } \\
\text { Table } 2 \text { - Characteristics of the types of cultivation }\end{array}$}} \\
\hline & & & \\
\hline Tipos de cultivo & Densidade (ind//m²) & \multicolumn{2}{|l|}{ Alimentação } \\
\hline Extensivo & 0,5 a 4 & \multicolumn{2}{|c|}{$\begin{array}{l}\text { Natural, baseada no plâncton e nutrientes que entram nos tanques por } \\
\text { meio da circulação da água }\end{array}$} \\
\hline Semi-intensivo & 6 a 20 & \multicolumn{2}{|c|}{$\begin{array}{l}85 \% \text { da alimentação é natural e o restante da alimentação é } \\
\text { complementada por rações }\end{array}$} \\
\hline Intensivo & 20 a 100 & \multicolumn{2}{|c|}{$75 \%$ da alimentação é ração } \\
\hline Hiper-intensivo & $>100$ & \multicolumn{2}{|c|}{$75 \%$ da alimentação é ração } \\
\hline
\end{tabular}

Adaptado de Kungvankij et al. (1989), Nunes et al. (1997), Pontes \& Arruda (2005), Nunes (2001) e Barros (2006)

Adpated from Kungvankij et al. (1989), Nunes et al. (1997), Pontes \& Arruda (2005), Nunes (2001) and Barros (2006)

Tabela 3 - Insumos utilizados na atividade carcinicultura

Table 3 - Products used in shrimp farming activity

\begin{tabular}{ll}
\hline Insumos & Utilização \\
\hline Rações & $\begin{array}{l}\text { Alimentação suplementar. Confeccionadas no empreendimento (com farelo de arroz, peixes, sapos e rãs } \\
\text { picados, moluscos) ou industrializadas }\end{array}$ \\
\hline Fertilizantes & $\begin{array}{l}\text { Aumentam a eficiência na produção de alimento natural. Promovem o aumento da produção primária, } \\
\text { subsidiando a produção secundária de bactérias, zooplâncton e organismos bentônicos }\end{array}$ \\
\hline Antibióticos & $\begin{array}{l}\text { Mantém a qualidade e a saúde dos camarões. Dentre as substâncias utilizadas destacam-se fluoroquinonas, } \\
\text { betalactâmicos, sulfonamidas, tetraciclinas, probióticos, entre outros }\end{array}$ \\
\hline \hline
\end{tabular}

Adaptado de Kungvankij et al. (1989), Qin et al. (1995), Burford et al. (2003), Mamani (2007) e Santos (2009)

Adpated from Kungvankij et al. (1989), Qin et al. (1995), Burford et al. (2003), Mamani (2007)and Santos (2009) 
Apesar da eficiência obtida no que se refere à produção final, os insumos utilizados na carcinicultura (Tabela 3) são compostos por uma variedade de produtos químicos e biológicos, os quais podem causar contaminação dos corpos d'água receptores de efluentes com nutrientes, metais e antibióticos, alguns dos quais podem ser interferentes endócrinos (Paéz-Osuna, 2001; Constanzo et al., 2004; Primavera, 2006; Ahn et al., 2010). Grande parte das carciniculturas não dispõe de tratamento dos efluentes. Entretanto, cabe mencionar que, em sistemas de cultivos sem renovação de água, a liberação de efluente para o ambiente é mínima.

\section{Aspectos legais}

A grande ampliação da carcinicultura no mundo ocorreu a partir das décadas de 70 e 80 (Páez-Osuna, 2001). Com o aumento do número de empreendimentos, houve um movimento para regulamentar essa atividade. Contudo, em muitos países, essa mudança não ocorreu de forma específica, sendo a carcinicultura, em vários casos, normalizada por inúmeros códigos e leis adaptados de instrumentos legais já vigentes. Certamente, essa adaptação gerou dificuldades para a compreensão e a adequada implementação das normas.

No Brasil, a resolução $n^{\circ} \quad 312 / 02$ do CONAMA (Conselho Nacional do Meio Ambiente) é um dos principais instrumentos que regem procedimentos para implantação e manutenção legal dos empreendimentos de carcinicultura. Essa resolução estabelece, por exemplo, a obrigatoriedade de realização de licenciamento ambiental e Estudos de Impacto Ambiental (EIA), para empreendimentos com área maior que 50 ha (Tabela 4). Complementarmente à resolução $\mathrm{n}^{\mathrm{o}} 312 / 02$ do CONAMA, a atividade de carcinicultura também está subordinada a outras leis no âmbito federal, como o Decreto-Lei no $24.348 / 34$, que regula a saúde do animal e a eliminação de espécimes infectados, e o Decreto-Lei $n^{\circ}$ 986/69, que trata da segurança alimentar. Estados, municípios e o Distrito Federal também podem atribuir leis e diretrizes próprias para tratar da atividade de carcinicultura (Araripe et al., 2006). Essa possibilidade de sobreposição de ações municipais, estaduais e federais na regulação das atividades de carcinicultura torna o sistema de regulamentação mais confuso e de difícil compreensão e, consequentemente, aplicação. $\mathrm{Na}$ costa brasileira, é possível observar casos que retratam o frequente fracasso no trabalho conjunto de agências de regulação em nível local, regional e nacional na administração dos recursos naturais.

No ano de 2012, entrou em vigor o novo Código Florestal brasileiro, que teve por objetivo buscar a proteção e o uso sustentável das florestas e da vegetação nativa, em conjunto com o desenvolvimento econômico. Esse Código estabelece que apicuns ("[...]áreas de solos hipersalinos situadas nas regiões entremarés superiores, inundadas apenas pelas marés de sizígias, que apresentam salinidade superior a $150 \%$, desprovidas de vegetação vascular [...]"),salgados ("[...] áreas situadas em regiões com frequências de inundações intermediárias entre marés de sizígias e de quadratura, com solos cuja salinidade varia entre 100 e $150 \%$, onde pode ocorrer a presença de vegetação herbácea específica [...]") e margens de rios e lagos podem ser utilizados em atividades de carcinicultura. Para tanto, alguns pré-requisitos previstos em lei devem ser observados (i.e., limite da área total a ser ocupada específica para cada Estado; proteção da integridade dos manguezais arbustivos e dos processos ecológicos essenciais relacionados com os manguezais; atividades

Tabela 4 - Normas estabelecidas na resolução CONAMA n ${ }^{\circ}$ 312/02

Table 4 - Standards established by CONAMA Resolution $n^{\circ}$ 312/02

\begin{tabular}{|c|c|}
\hline \multirow[t]{5}{*}{ CONAMA n' $312 / 02$} & Normas \\
\hline & $\begin{array}{l}\text { Obriga que o empreendimento de carcinicultura em zona costeira realize licenciamento } \\
\text { ambiental }\end{array}$ \\
\hline & $\begin{array}{l}\text { Exige a apresentação de Estudos de Impacto Ambiental (EIA) para empreendimentos com área } \\
\quad>50 \text { ha e potencialmente causadores de degradação ambiental }\end{array}$ \\
\hline & $\begin{array}{l}\text { Proibe que a atividade de carcinicultura seja implantada em áreas de manguezal e em regiões } \\
\text { que prejudiquem atividades tradicionais de sobrevivência das comunidades locais }\end{array}$ \\
\hline & $\begin{array}{l}\text { Determina que o empreendedor deva controlar e tratar os efluentes da atividade, com a } \\
\text { obrigatoriedade de que a água utilizada na carcinicultura retorne ao ambiente com qualidade } \\
\text { igual a que foi retirada do seu curso natural }\end{array}$ \\
\hline
\end{tabular}


tradicionais de sobrevivência das comunidades locais) $\left(\right.$ Lei $\mathrm{n}^{\circ} 12.651$, de 25 de maio de licenciamento da atividade e das instalações pelo órgão ambiental estadual; recolhimento, tratamento e disposição adequados dos efluentes e resíduos produzidos durante o ciclo produtivo; respeito às atividades tradicionais de sobrevivência das comunidades locais) (Lei $\mathrm{n}^{\circ}$ 12.651, de 25 de maio de 2012). A aprovação dessa lei acarretou inúmeros protestos por parte da comunidade acadêmica, assim como dos ambientalistas, levando a uma série de discussões a respeito da eficácia do Código.

As margens de rios e lagos, apesar de continuarem sendo classificadas como áreas de Preservação Permanente (APP), foram autorizadas a serem utilizadas para implantação da estrutura física da prática da carcinicultura. No entanto, o Código não deixa claro se esta liberação está associada a formas específicas de cultivo. Não determina, por exemplo, o uso de tanques redes (gaiolas flutuantes) ou o uso de tanques escavados, sendo que a primeira opção causa menos impactos ambientais e a segunda poderia acarretar problemas quanto ao processo de assoreamento e no que se refere à manutenção do equilíbrio ecológico, funções atribuídas às APPs da margens de rios e lagos.

Com relação às áreas de apicum e salgado, os parlamentares utilizaram o argumento de que essas áreas não pertencem ao ecossistema de manguezal. $\mathrm{Na}$ realidade, acredita-se que a liberação das áreas de apicum e salgado para a criação de camarões em cativeiro está relacionada apenas a fatores econômicos, e não aos aspectos técnico-científicos.

Além das regularizações específicas de cada país, a Organização de Agricultura e Alimentação (FAO) das Nações Unidas (ONU) elaborou um código de conduta
(Código de Conduta para a Pesca Responsável - CCRF) (FAO, 1995) visando ao desenvolvimento de uma aquicultura sustentável, buscando uma produtividade com o mínimo de prejuízo para o ambiente, abrangendo, também, a questão da sobrepesca, que pode ter como consequência a marginalização dos pescadores artesanais.

O CCRF serviu de base para a criação de outros documentos, tais como GAP, BPM e as Boas Práticas de Conduta da Carcinicultura (Tabela 5), que buscam pôr em prática as propostas feitas no CCRF e complementar aspectos que não foram mencionados neste Código. O GAP trabalha mais especificamente com aspectos da segurança dos alimentos produzidos, e o BMP visa incluir práticas relevantes para a sustentabilidade das fazendas e aspectos relacionados à degradação ambiental, focando nos problemas técnicos apresentados para esse setor de produção.

No Brasil, foi proposto pela $\mathrm{ABCC}$, juntamente com seus associados e colaboradores, um Código de Conduta denominado Boas Práticas de Conduta da Carcinicultura, que aborda aspectos presentes no GAP e no BMP. Nesse Código, são mencionadas as questões relativas às condições higiénico sanitárias dos alimentos e são estabelecidos compromissos das empresas para aspectos técnicos, ambientais e sociais. Dessa forma, o Código busca evitar ou minimizar impactos ambientais e sociais, contribuindo, assim, para melhorar as condições ambientais e sociais da área de influência das fazendas de cultivo.

Em suma, temos que esses documentos são uma espécie de manual de instrução para cultivos cujos objetivos estão relacionados à conservação, à gestão e ao desenvolvimento dos recursos aquáticos vivos (Alam et al, 2005). Deve ser salientado que esses códigos não

Tabela 5 - Sumário dos documentos que estabelecem diretrizes para a atividade de criação de camarão

Table 5 - Summary of documents that establish guidelines for the activity of shrimp farming
Diretrizes
Atividades

$\mathrm{GAP}^{1}$ (Práticas da Boa Aquicultura)

Aborda questões como a escolha do local; gestão das fazendas, da saúde dos organismos, dos alimentos e da alimentação; manutenção dos registros; aplicação de drogas e produtos químicos para assegurar a não contaminação dos alimentos

$\mathrm{BMP}^{2}$ (Práticas de Melhor Manejo)

Suscita a questão da sustentabilidade das fazendas e a questão da degradação ambiental, buscando abordar problemas técnicos

Boas práticas de conduta do carcinicultura

Elabora documentos para direcionar as boas práticas de conduta do carcinicultor, normas gerais sobre as condições higiênico-sanitárias dos alimentos, e estabelecem compromissos das empresas para aspectos, técnicos, ambientais e sociais

${ }^{1}$ Good agriculture practices; ${ }^{2}$ Better management practices

ABCC (2004), ABCC (2005), Bene (2005), Yamprayoon \& Sukhumparnich (2010) 
têm força de lei, são documentos orientadores, que visam à adoção voluntária por parte de governos de Estado, sugerindo, dessa forma, aos produtores implementar condutas corretas em termos do estabelecimento, manejo, sanidade e uso de produtos para a manutenção dos viveiros e a minimização dos impactos relacionados à atividade.

Ao comparar a legislação brasileira vigente com a de outros países que se destacam como produtores, tais como Chile (Ley 19300/94, Decreto n. ${ }^{\circ} 90$ de 2000 e Decreto n. ${ }^{\circ} 1$ de 1992), China (Marine Environment Protection Law 1982, Law on the Prevention and Control of Water Pollution 1984/1996 e Rules for implementation of the the prevention and control of water pollution - Decree no. 1, de 1989), Equador (Decreto n. ${ }^{\circ} 1.732$ de 2009) e México (Reglamento de la Ley General del Equilibrio Ecológico y la Protección al Ambiente en Materia de Evaluación del Impacto Ambiental, de 2000) (Tabela 6), podem ser observados muitos pontos em comum, o que nos permite perceber que a legislação brasileira está de acordo com as normas vigentes em outros países.

Nos países analisados (Brasil, Chile, China e México), o controle de doenças, por exemplo, quando não especificado, é baseado em leis utilizadas para o cultivo de peixes, havendo restrições ao uso de drogas. Diferentes aspectos sobre o controle de doenças (e.g. ações emergenciais, preventivas, de vigilância e manejo) são frequentemente abordados. No Brasil, o controle de doenças é fiscalizado por meio de leis Estaduais e Federais, sendo função do Estado controlar aspectos relativos à saúde animal. Além disso, todos os estabelecimentos de aquicultura estão sujeitas à supervisão do Serviço Veterinário Oficial. No México, o controle de doenças é regulado por duas leis: uma aplicável a todos os tipos de cultivo de animais aquáticos e outra que contém disposições detalhadas sobre questões relativas à saúde de animais aquáticos. Apesar de o Chile apresentar uma lei para o controle de doenças, esta fica restrita à piscicultura. $\mathrm{O}$ mesmo ocorre na China, onde a lei foi sancionada para o cultivo de peixes e nela tem-se uma descrição dos procedimentos para controle e tratamento de doenças, incluindo medidas de quarentena importantes para que as doenças não se disseminem pela região.

De uma maneira geral, o uso de drogas para manutenção do cultivo é bem regulamentado, sendo limitado ou proibido o uso de certas substâncias. Todavia, o Brasil não apresenta legislação específica para o controle das drogas utilizadas. Cabe ressaltar que ainda não existem muitos estudos na literatura relatando quais seriam as drogas mais utilizadas nos sistemas de carcinicultura desenvolvidos no Brasil, bem como seus potenciais impactos nas variáveis abióticas e na fauna dos corpos receptores (e.g., Sotomayor \& Balcázar, 2003; Toro, 2005; Mamani, 2007; Santos, 2009).

Muitas fazendas de carcinicultura no nordeste brasileiro, a exemplo do estado da Bahia, são ilegais ou têm legalidade duvidosa (Garcia, 2012), devido a diferentes artifícios e/ou lacunas presentes na legislação. Como resultado, percebeu-se que as informações sobre a utilização de drogas nessas fazendas não foram apropriadamente documentadas e/ ou divulgadas pelos órgãos ambientais.

Adicionalmente, as pesquisas de campo realizadas pelos autores deste trabalho mostraram que dados sobre a utilização de insumos na carcinicultura praticada na Baía de Todos os Santos, Bahia, em geral, não são fornecidos pelos produtores e/ou trabalhadores das fazendas, seja por desconhecimento ou por medo de disponibilizar informações sobre fazendas não legalizadas.

Quanto às rações a serem empregadas na alimentação dos camarões, existe um controle específico, o que garantiria ao consumidor a certeza de que o cultivo foi abastecido com uma alimentação balanceada e com produtos de qualidade. O controle da alimentação empregada nas fazendas ocorre mediante a apreciação de relatórios fornecidos pelos donos dos empreendimentos às instituições fiscalizadoras com informações sobre o tipo de alimento utilizado e uma relação dos produtos que foram adicionados à ração. A qualidade dos alimentos, entretanto, não pode ser assegurada no caso dos empreendimentos não licenciados.

Diante do que foi apresentado, percebe-se que, no Brasil, a carcinicultura está regulamentada e subordinada à legislação vigente, desde a implantação até à venda do produto final. Conforme previamente discutido, as leis, diretrizes e/ou normas em vigor no Brasil são similares às existentes em outros países que também se destacam no cenário da carcinicultura. Nesse contexto, cabe ressaltar o código de conduta internacional, que é um instrumento adequado para guiar o desenvolvimento da carcinicultura de forma rentável e, concomitantemente, ambientalmente sustentável. A legislação brasileira, entretanto, é claramente omissa no controle do uso de drogas no cultivo, uma vez que não possui regras específicas. Esse aspecto é bastante relevante, visto que o impacto negativo dos efeitos de drogas, como antibióticos e hormônios, na fauna e na flora dos corpos receptores de efluentes, nos ecossistemas costeiros, é desconhecido.

Outro aspecto não menos importante é a questão da ilegalidade de muitos empreendimentos de carcinicultura. Apesar de não haver na literatura, até o 
Tabela 6 -Comparação da legislação para cultivo de camarões em diversos países

Table 6 - Comparison of legislation for shrimp farming in several countries

\begin{tabular}{|c|c|c|c|c|}
\hline & $\begin{array}{l}\text { Princípios base dos Guias e } \\
\text { Códigos de Conduta }\end{array}$ & Controle de doenças & Drogas & Alimentação \\
\hline Brasil & $\begin{array}{l}\text { Organizados pela ABCC } \\
\text { (Associação Brasileira de } \\
\text { Criadores de Camarão). }\end{array}$ & $\begin{array}{l}\text { Fiscalizado em nível estadual } \\
\text { pelo Departamento de Defesa } \\
\text { Animal (DDA) e em nível } \\
\text { Federal pela Delegacia Federal } \\
\text { de Agricultura (DFA). }\end{array}$ & Não há regras específicas. & $\begin{array}{l}\text { Lei } \mathrm{N}^{\mathrm{o}} 6.198 / 74 \text { institui controles sanitários nos } \\
\text { alimentos usados no cultivo. Decreto } \mathrm{N}^{\circ} 80.583 / 77 \\
\text { estabelece as normas de qualidade de sal a ser } \\
\text { utilizado na alimentação. }\end{array}$ \\
\hline Chile & $\begin{array}{l}\text { Não existem diretrizes ou } \\
\text { códigos de conduta. }\end{array}$ & $\begin{array}{l}\text { Específico para cultivo de } \\
\text { peixes. }\end{array}$ & $\begin{array}{l}\text { Todos os medicamentos veterinários e de controle } \\
\text { sanitário devem ser inspecionados. } \\
\text { Limitações ou proibições de medicamentos } \\
\text { contendo substâncias específicas (i.e. cetamina ou } \\
\text { derivados de nitrofuranos). }\end{array}$ & $\begin{array}{l}\text { Regulamento para controle da saúde por meio da } \\
\text { introdução de alimentos e produtos orgânicos a } \\
\text { serem utilizados para fins de aquicultura está em } \\
\text { processo de adoção. }\end{array}$ \\
\hline China & $\begin{array}{l}\text { Inúmeras diretrizes em nível } \\
\text { nacional e provincial, } \\
\text { abrangendo vários temas. }\end{array}$ & $\begin{array}{l}\text { A Law on Animal Diseases } \\
\text { (1997) descreve procedimentos } \\
\text { para controle de doenças. }\end{array}$ & $\begin{array}{l}\text { Produção, importação, exportação, armazenamento, } \\
\text { uso e eliminação de certos tipos de produtos quí- } \\
\text { micos são regulados. } \\
\text { Existência de sistemas de controle de novas drogas } \\
\text { e monitoramento de segurança dos medicamentos } \\
\text { utilizados. }\end{array}$ & $\begin{array}{l}\text { Fortalecimento da administração de aditivos, } \\
\text { melhorando a qualidade, aumentando o } \\
\text { desenvolvimento da produção e a segurança da } \\
\text { saúde pública. }\end{array}$ \\
\hline Equador & $\begin{array}{l}\text { Norma de certificação para a } \\
\text { carcinicultura orgânica. }\end{array}$ & Não há regras específicas. & $\begin{array}{l}\text { Restrições à utilização de medicamentos veteri- } \\
\text { nários. } \\
\text { Manutenção de um cadastro dos produtos veteri- } \\
\text { nários autorizados. } \\
\text { O uso de cloranfenicol é proibido. }\end{array}$ & $\begin{array}{l}\text { Estabelece que a farinha de peixe para ração só } \\
\text { poderá ser produzida com excedentes e/ou de } \\
\text { restos do processo de beneficiamento do produto } \\
\text { para o mercado. }\end{array}$ \\
\hline México & $\begin{array}{l}\text { Não há diretrizes ou códigos } \\
\text { de conduta. }\end{array}$ & $\begin{array}{l}\text { Regulado pela Ley Federal de } \\
\text { Sanidad Animal (1993) e } \\
\text { Fisheries Law (para organismos } \\
\text { aquáticos em geral). }\end{array}$ & $\begin{array}{l}\text { Drogas, alimentos e hormônios a serem utilizados } \\
\text { são regulados. } \\
\text { Estabelecimento de limites mínimos e máximos de } \\
\text { uso e aplicação de antibióticos. } \\
\text { Novos fármacos devem ser aprovados previamente. }\end{array}$ & $\begin{array}{l}\text { Produtores devem informar tipos e doses de } \\
\text { medicamentos adicionados à ração utilizada. } \\
\text { É proibida a utilização de alimentos baseado em } \\
\text { crustáceos frescos, exceto para artemia (Artemia } \\
\text { spp) }\end{array}$ \\
\hline
\end{tabular}

Adaptado NALO (2005) / Adapted from NALO (2005) 
momento da elaboração desta revisão, um banco de dados para o território nacional e/ou estadual contabilizando o número de fazendas em condições irregulares, um levantamento de dados indica que o número de fazendas nessa situação é substancial (IMA, 2004; IBAMA, 2005; Garcia, 2012; Latorre, 2012; Mialhe et al., 2013) e merece a atenção dos órgãos competentes. Na prática, isso significa que a qualidade dos camarões produzidos, em termos de segurança alimentar, e os impactos socioambientais associados a esta atividade não são monitorados e/ou mitigados ou coibidos. Em larga escala espacial e, também, em longo prazo, atividades irregulares poderão comprometer de forma irreversível os serviços ecológicos promovidos pelos ecossistemas adjacentes às fazendas, trazendo, também, prejuízos quiçá irreparáveis para as comunidades tradicionais que dependem dos recursos obtidos nesses ecossistemas.

\section{Impactos negativos gerados pela carcinicultura}

$\mathrm{O}$ rápido crescimento da atividade da carcinicultura causou a conversão de extensas áreas costeiras em zonas de produção de camarão, gerando impactos sociais, econômicos e ambientais em várias regiões ao redor do planeta (e.g., Barbier \& Strand, 1998; Primavera, 2006; Ahn et al., 2010; Lacerda et al., 2011; Mialhe et al., 2013; Queiroz et al., 2013; Sahu et al., 2013). Os impactos negativos podem ser de curto ou longo prazo, envolvendo o desequilíbrio ecológico, a contaminação ambiental, surtos de doenças, entre outros (Paul \& Vogl, 2011). A magnitude dos impactos gerados depende de muitos fatores, tais como: localização das fazendas; local da construção dos tanques; manejo dos viveiros; uso de tecnologias durante as operações nos viveiros; tipo de cultivo; escala de produção e capacidade de assimilação do sistema; hidrodinâmica dos corpos receptores (AlonsoRodriguez \& Páez-Osuna, 2003; Constanzo et al., 2004), entre outros.

Entre os inúmeros problemas associados à carcinicultura, merece destaque a localização e a construção dos tanques de cultivo. Em várias regiões, as florestas de manguezais são frequentemente derrubadas e ocupadas para a implantação de fazendas de criação de camarão devido à ampla disponibilidade de água de qualidade apropriada para o cultivo e ao baixo valor de mercado (Nascimento, 2007). No Brasil, esse problema ainda pode ser agravado com a aprovação do novo Código Florestal.

Um dos pontos mais controversos do novo Código é o fato de que algumas áreas de Preservação Permanente (APPs) tiveram suas restrições de uso alteradas. As áreas de apicuns e salgados, por exemplo, foram liberadas para cultivo de camarões (Lei n ${ }^{\circ} 12.651$, de 25 de maio de 2012).
A permissão do uso de apicuns e salgados para desenvolvimento da atividade levantou uma série de discussões. Os apicuns são ambientes pouco estudados, os conhecimentos sobre eles obtidos estão geralmente associados a estudos de manguezais ou ao mapeamento de zonas costeiras (Hadlich \& Ucha, 2009). O mesmo ocorre para as áreas de salgados, que também constituem um ecossistema pouco estudado. A escassez de informações mais específicas a respeito dessas áreas dificulta a previsão e/ou prevenção de possíveis processos de degradação associados à atividade de cultivo.

$\mathrm{Na}$ tentativa de assegurar que somente os apicuns e os salgados serão utilizados como áreas de cultivo, alguns pré-requisitos são necessários, como foi apresentado anteriormente. Porém, o estabelecimento desses prérequisitos não impede que o cultivo se estenda para as áreas de manguezais e tampouco que esses mesmos prérequisitos sejam atendidos. Isso se deve ao fato de que os órgãos ambientais responsáveis normalmente não possuem um esquema de fiscalização pontual e frequente.

A expansão do cultivo até a área de manguezal tem diversas consequências, dentre elas destaca-se a perda de produtos e serviços que são fornecidos por ele: a vegetação de manguezal oferece abrigo, alimentação, zona de reprodução, proteção da linha de costa contra erosão e tempestades, entre outros serviços (Primavera, 1997; 2006). A perda dessas áreas e serviços pode ocorrer por meio da conversão, privatização e expropriação de terras. Estima-se que a floresta de manguezal intacta tenha um valor econômico aproximadamente $70 \%$ maior do que quando convertida em fazenda de camarão (Balmford et al., 2002). O impacto causado pelo uso de áreas de manguezais para a carcinicultura, no que se refere à mudança na paisagem local, é similar, segundo Meirelles (2005), ao que acontece na especulação imobiliária; ou seja, nesses dois casos, ocorre uma alteração significativa da paisagem, comprometendo os ecossistemas costeiros, podendo resultar no deslocamento e na migração das comunidades tradicionais.

Os problemas de impactos ambientais negativos não ficam restritos à fase de implantação. A fase da despesca (Tabela 1), na qual são lançados no ambiente os efluentes das fazendas com todos os insumos utilizados no cultivo, tem sido apontada como a fase que mais gera danos ao ambiente (Brummett, 2003; Páez-Osuna et al., 2003). Entretanto, existe uma ausência de informação sobre as quantidades e a qualidade dos insumos usados, o que certamente dificulta a mensuração da magnitude e da extensão dos impactos causados por esses produtos (Graslünd \& Bengtsson, 2001). De uma maneira geral, os potenciais contaminantes introduzidos nos corpos receptores junto 
com os efluentes são: i) antibióticos e agentes antimicrobianos (Gräslund \& Bengtsson, 2001; Anh et al., 2010); ii) nutrientes (e.g. amônia, nitrato, fosfato) que podem gerar eutrofização de corpos d'água (Jones et al., 2001; Gál et al., 2003; Figueirêdo et al., 2006; Anh et al., 2010; Souza, 2013) e/ou proliferação de algas produtoras de toxinas; iii) e metais traços e maiores, incluindo Hg (Lacerda et al., 2006 e 2009; Lacerda et al., 2011; Costa et al., 2013).

Antibióticos e antimicrobianos são utilizados com fins terapêuticos, profiláticos e como promotores de crescimento, para melhorar aassimilação de alimentos e, consequentemente, aumentar a produção (Barton, 2000). Estima-se que entre 1.000 e 2.000 ton $/ \mathrm{m}^{2} /$ ano de antibióticos e antimicrobianos sejam utilizados em fazendas da Ásia e da América Latina (Toro, 2005), destacando-se os antibióticos do grupo das fluoroquinonas (e.g. sarafloxacina e norfloxacina) e os antimicrobianos do grupo dos betalactâmicos (e.g. sulfonamidas, tetraciclinas, aminoglicosídeos, macrolídeos, quinolonas e anfenicóis) (Mamani, 2007; Santos, 2009). De acordo com Le \& Munekage (2004), os resíduos de antibióticos no ambiente podem afetar os ecossistemas costeiros e marinhos e a saúde humana. No entanto, estudos sobre a ocorrência desses fármacos no ambiente, especialmente em água do mar, ainda são limitados, de forma que não é possível avaliar a real contribuição da carcinicultura na introdução desses compostos em corpos d'água receptores e sua consequência.

$\mathrm{O}$ aporte de nutrientes descartados diretamente no ambiente sem tratamento prévio, oriundos do acúmulo de restos de alimentos, fezes e fragmentos de animais nos fundos dos tanques, pode causar deterioração das águas dos corpos receptores e/ou sua eutrofização (Thompson et al., 2002). Como resultado, a eutrofização e a sedimentação decorrentes da dispo-sição dos efluentes levam à modificação do habitat, potencialmente provocando a perda da fauna, sobretudo de organismos bentônicos (Azevêdo, 2005).

Além de nutrientes, outro grupo importante de contaminantes são os metais traço que são inseridos nos tanques de cultivo através dos alimentos e insumos usados na carcinicultura. A elevada concentração de metais tóxicos tem sido uma das causas atribuídas aos baixos índices de produtividade de fazendas de carcinicultura (Gosavi et al., 2004). Os metais podem causar alteração na taxa de sobrevivência, no crescimento, no comportamento alimentar, na frequência das ecdises, na capacidade de osmo-regulação e na respiração de camarões (Chen \& Lin, 2001; Hossain \& Khan, 2001; Wu \& Chen, 2005). Adicionalmente, o lançamento de água e sedimentos contaminados dos tanques de carcinicultura no ambiente pode causar efeitos adversos na qualidade da água, na fauna e na flora presentes nas áreas adjacentes às fazendas (Souza, 2013).
Outra problemática associada com a atividade de criação de camarões refere-se ao abandono das áreas de cultivo após anos de exploração. O tempo médio de vida útil de um tanque de carcinicultura, devido a problemas decorrentes da autopoluição e a doenças, é entre 7 e 15 anos, para fazendas com boa gestão, e entre 5 e 10 anos, para fazendas com sistemas intensivo e semi-intensivo de produção (Flaherty \& Karnjanakesorn, 1995; Primavera, 1997). Esse tempo pode ser menor em áreas de manguezal devido à elevada concentração de matéria orgânica e acidez dos solos (Jahan, 2013).

Ao esgotar a área onde é implantada a atividadade de aquicultura, os produtores migram para novos locais. Essa migração foi denominada por Ellison (2008) de "roving banditry" (banditismo itinerante) e deixa para trás solos com erosão acelerada, diminuição da capacidade de armazenamento de água, redução na biodiversidade da fauna (e.g. organismos bentônicos) e pobres em matéria orgânica, devido ao aumento do escoamento superficial e subsuperficial (Stevenson, 1997); além de alterações de propriedades físico-químicas da água, devido à liberação de precipitados de ferro, e susceptibilidade a riscos ecológicos, devido às concentrações de cobre, cádmio e manganês nos viveiros abandonadas (Sammut et al., 1996; Visuthismajarn et al., 2005).

Ellison (2008) observou que os envolvidos, normalmente, não possuem nenhuma ligação direta com as comunidades locais e nenhum incentivo, por parte dos órgãos relacionados à atividade, para gerir de forma sustentável o cultivo. Dessa forma, eles cortam os manguezais para a implantação dos tanques de cultivo, promovendo todas as modificações necessárias para a implantação da fazenda, e, ao esgotarem os recursos naturais necessários para a manutenção da produção e, com isso, para a obtenção de lucros, seguem para outra área e recomeçam o processo.

De acordo com Visuthismajarn et al. (2005), os efeitos ambientais e os riscos ecológicos relacionados ao abandono de carciniculturas são pouco conhecidos; no entanto, tem sido observado, nos últimos anos, uma preocupação crescente quanto a esse assunto.

A importância da dimensão social tem sido frequentemente neglicenciada nas avaliações de impactos negativos associados à carcinicultura. $O$ processo de implantação das fazendas pode, por exemplo, gerar a marginalização, o desemprego rural e a migração da população costeira, além de trazer insegurança na disponibilidade de alimentos, interrupção dos sistemas tradicionais de produção, distribuição e relações sociais, acarretando, dessa forma, distúrbios e conflitossociais (Azevêdo, 2005; Alam et al., 2005; Queiroz et al., 2013). 
Segundo Neiland et al. (2001), os conflitos sociais estão fortemente associados ao sistema e aos direitos de uso da propriedade existentes no país. Em áreas de manguezais, ao longo de toda a costa brasileira, é comum, mesmo que ilegal, a concessão de áreas para empreendedores sem a devida consideração e ponderação sobre as atividades previamente existentes na área e/ou as atividades culturais e de subsistência praticadas pelas comunidades tradicionais locais. Abreu et al. (2011) mostraram que criadores de camarão pareciam ser indiferentes com relação ao desenvolvimento de impacto social como consequência da atividade desenvolvida por eles. Os autores também indicaram que os carcinicultores não interagem com a população local, e, portanto, as comunidades não reconhecem a atividade como um projeto econômico a ser incentivado.

Em suma, a busca pela prosperidade e lucratividade das atividades de carcinicultura, somada, muitas vezes, à ineficiência dos órgãos de governo nas atividades de licenciamento e fiscalização, e a não observância e/ou a permissividade das legislações ambientais podem levar a atividade de carcinicultura a causar uma série de impactos socioeconômicos e ambientais.

\section{Alternativas mitigadoras aplicadas à carcinicultura}

Os impactos aqui relatados, de certa forma, refletem a frequente falta de planejamento no desenvolvimento da carcinicultura no Brasil e no mundo. Quando falamos em planejamento das atividades de carcinicultura, foram considerados os princípios defendidos pela BMP (Práticas de Melhor Manejo) e pela GAP (Práticas da Boa Aquicultura) (Tabela 5).

Muitos são os potenciais impactos associados à carcinicultura, uma vez que a atividade, muitas vezes, não é concebida de forma planejada, resultando na degradação de áreas naturais e em uma série de outros impactos (Oliveira, 2009). A detecção de impactos, entretanto, não é uma tarefa simples, visto sua comple-xidade e seu caráter multidisciplinar.

Biao \& Kaijin (2007) relataram que essa dificuldade reside no fato de que o lançamento de contaminantes não é sempre identificado. Com relação à contaminação química, por exemplo, são necessários testes laboratoriais específicos. Em casos extremos, a morte massiva de camarões e outros organismos aquáticos é indicativa de um problema de contaminação.

Medidas de gestão para resolver ou mitigar problemas de impacto ambiental causados pelo desenvolvimento do cultivo tornaram-se urgentes e obrigatórias. No entanto, apesar dessa urgência, medidas específicas para o desenvolvimento sustentável da atividade têm sido pouco divulgadas e/ou aplicadas, mas há indícios de que os países dependentes economicamente do cultivo estão em busca, visando encontrar o caminho para uma carcinicultura sustentável.
A maioria dos problemas ambientais associados à carcinicultura está relacionada com os efluentes que são liberados no ambiente sem tratamento prévio. A abordagem mais tradicional adotada por muitas fazendas para lidar com esse problema, segundo Lin et al. (2002), reside no tratamento convencional de águas residuais e na remoção de sólidos por sedimentação. No entanto, o tratamento convencional apresenta como desvantagens a produção de lodo, a elevada demanda por energia e a necessidade frequente de manutenção. Como resultado, alternativas mitigadoras mais eficientes têm sido pesquisadas, testadas e aplicadas.

Biao \& Kaijin (2007) apresentaram duas estratégias promissoras como alternativas específicas para reduzir a liberação de nutrientes gerados pela carcinicultura. A primeira, com uma abordagem ecológica ou orgânica, que tem como princípio fundamental minimizar o impacto ambiental durante o desenvolvimento da atividade, o que implica, consequentemente, em um cultivo de menor intensidade. Nesse tipo de abordagem, os esforços para produção devem estar em sincronia com os processos naturais do ecossistema. Seguindo a lógica dessa abordagem, pode-se realizar um cultivo integrado (e.g. policultura de bivalves, peixes e camarões), em que os recursos necessários (e.g. água, ração) e os resíduos gerados são recirculados dentro da fazenda, mais especificamente nos tanques, evitando, dessa forma, o empobrecimento ou a sobrecarga do ambiente no qual o empreendimento está inserido. No sistema de policultura, a água utilizada nos tanques de cultivo de camarão é usada na alimentação das ostras (Jakob et al., 1993). No entanto, Biao \& Kaijin (2007) apresentam como desvantagem dessa abordagem o fato de que, sendo um cultivo caracteristicamente de baixa intensidade, tais sistemas exigem tanques com áreas maiores que aquelas utilizadas em sistemas intensivos de produção. Esse modo de produção requer mais pesquisas para demonstrar, de fato, suas vantagens e convencer, dessa forma, que os carcinicultores o adotem em suas fazendas.

A segunda estratégia apresenta uma abordagem tecnológica ou biotecnológica (Biao \& Kaijin, 2007) que tende a impulsionar o desenvolvimento em direção ao uso de sistemas hiper-intensivos, que são isolados do ambiente e implementam o mecanismo zero de descarga, ou seja, os efluentes não são liberados no ambiente. Esse sistema envolve o tratamento e a recirculação dos resíduos dos viveiros, esterilização dos tanques com antibióticos, cloro e formaldeído, entre outras substâncias. Essa estratégia, no entanto, exige um elevado investimento de capital, limitando essa opção apenas aos empreendedores de grande porte, ao passo que apresenta como vantagem um elevado rendimento, com o mínimo de prejuízo ambiental e na produção, já que todas as etapas são controladas com rigor. 
De modo geral, essas duas estratégias têm sido aplicadas nos cultivos, mas não visando testar sua eficiência, e sim em busca de uma melhor forma de produção, alcançando maior lucratividade. Muitas vezes, as estratégias aqui apresentadas são utilizadas pelos empreendedores sem o conhecimento de fato da existência dessas duas abordagens, assim como suas vantagens e desvantagens. São adotadas a partir do conhecimento empírico, adquirido a partir das experiências diárias.

Read \& Fernandes (2003) sugerem que um gerênciamento pró-ativo resolveria potenciais conflitos relacionados à demanda pelos recursos costeiros. Esses conflitos envolvem questões que surgem durante o planejamento do empreendimento e se prolongam até as etapas de desenvolvimentos do cultivo propriamente dito. Tais conflitos poderiam ser resolvidos por meio da aplicação do chamado Gestão Integrada da Zona Costeira, que visa, de modo geral, administrar os recursos naturais da zona costeira de forma sustentável.

Os problemas sociais relacionados à carcinicultura podem ser minimizados oferecendo empregos nas fazendas aos integrantes das comunidades ribeirinhas, que muitas vezes não obtêm a partir da pesca o suficiente para a sua sobrevivência e, por falta de instrução escolar, não conseguem empregos fixos.

$\mathrm{O}$ cultivo tem um impacto positivo de ordem social e econômica nas regiões nas quais ele tem influência, podendo ser considerado motor de renda e emprego para os habitantes locais, principalmente para os pescadores artesanais, que foram prejudicados com a escassez dos estoques naturais de camarão marinho. Os empregos gerados são estáveis e privilegiam diretamente a comunidade ribeirinha, uma vez que não requerem educação formal elevada para a execução das tarefas (Costa, 2009; Cavalcanti, 2012). Entretanto, nem todas as comunidades optam por participar desse processo produtivo. A incorporação de comunidades tradicionais nos sistemas de carcinicultura não é um problema simples e requer ampla discussão com a comunidade.

Para aproveitar a mão de obra dos moradores das comunidades ribeirinhas, pode-se incentivá-los a cuidar das fazendas de camarões que são abandonadas após anos de cultivo. Barbier (2006) observou que as áreas degradadas pelo cultivo podem ser recuperadas pelas comunidades locais e pelas partes interessadas, desde que elas reconheçam, nesse processo, uma forma de obtenção de renda. Uma vez que o processo de recuperação seja realizado, esses mesmos grupos passam a ser responsáveis pela conservação, visando manter, dessa forma, a sua fonte de renda.

Abreu et al. (2011) apontaram que deve ser reforçada uma relação mais estreita entre a indústria e a comunidade local, por meio do desenvolvimento de projetos sociais com foco na melhoria da qualidade de vida nas comunidades locais, melhorando, assim, a sua imagem e, consequentemente, reduzindo conflitos. Uma das formas adotadas para solucionar os problemas sociais que surgem com essa atividade é integrar as comunidades que dependem direta e indiretamente das áreas costeiras ao sistema de cultivo. A maneira dessa integração, entretanto, deve ser discutida entre a comunidade e os empreendedores. Cabe lembrar que a opção de participação das comunidades tradicionais no processo produtivo nem sempre é uma escolha voluntária, e sim a única alternativa viável em substituição às atividades tradicionais previamente praticadas pelas comunidades.

Para o tratamento de águas sujeitas a altas cargas de contaminantes orgânicos, uma alternativa defendida atualmente é a biorremediação (Milanese et al., 2003). Nesse processo, ocorre a eliminação, atenuação ou transformação de contaminantes pelo uso de processos biológicos (Lynch \& Moffat, 2005). Já Gutierrez-Wing \& Malone (2006) defendem que a remoção da maior parte das substâncias contaminantes na água deve ser realizada por meio de Sistemas de Recirculação de Água (RAS). Segundo Martins et al. (2010), esse sistema foi desenvolvido para responder às crescentes regulamentações ambientais em países com acesso limitado à terra e à água. Foi a partir da década de 80 que estudos visando ao uso de sistemas de recirculação se intensificaram no Japão, nos Estados Unidos, em Israel e em diversos países europeus, e, diante dos resultados positivos, passaram a ser adotados pelos grandes empreendimentos em outros países, assim como no Brasil, sendo inicialmente instalados no nosso país em algumas fazendas que trabalhavam com peixes ornamentais, com laboratórios de reprodução de tilápia e com processos de produção de larvas de camarão (Kubitza, 2006).

O RAS oferece vantagens em termos de redução do consumo de água (Verdegem et al. 2006), melhores oportunidades de disposição dos resíduos e reciclagem de nutrientes (Piedrahita, 2003), melhor higiene e tratamento de doenças (Summerfelt et al, 2009; Tal et al, 2009). Uma das maiores dificuldades relatadas para a implantação do RAS é o elevado capital de investimento necessário e o longo período dedicado à sua implantação (em torno de 8 anos), fazendo com que o RAS não seja economicamente viável em curto prazo de tempo (Badiola et al., 2012).

No que se refere à adubação e à alimentação, Sahu et al. (2013) sugerem que a quantidade de adubo a ser aplicada seja calculada de modo que não gere excedente. Adicionalmente, esses autores propõem que a alimentação seja fornecida por meio de alimentadores (e.g. do tipo bandejas) dispostos ao longo dos tanques, evitando o lançamento excessivo de ração e, portanto, seu acúmulo nos tanques. 
A Tecnologia de Bio-Flocos (BFT) é uma técnica que tem ganhado espaço no que se refere ao controle de impactos. Essa é caracterizada por utilizar altas densidades de cultivo, promovendo o aumento da produtividade (i.e. biossegurança, evitando a fuga da espécie cultivada para o ecossistema), e pela pouca ou nenhuma troca de água, o que reduz significativamente a emissão de efluentes para o meio ambiente (Mcintosh et al., 2000; Burford et al., 2003). De acordo com Crab et al. (2007), a BFT proporciona um método sustentável para manter a qualidade da água em sistemas de cultivo.

Para sanar problemas relacionados ao uso de antibióti$\cos$ e antimicrobianos, a Associação Brasileira de Criadores de Camarão (ABCC, 2004) recomenda que essas substâncias sejam usadas na forma de ração medicada, para garantir as concentrações teciduais (Concentração Inibitória Mínima - CIM) necessárias para a completa eliminação do patógeno no organismo do camarão. Dessa forma, utiliza-se a mínima quantidade de fármacos necessária para o tratamento da enfermidade. Uma alternativa defendida por Sotomayor \& Balcázar (2003) consiste em restrições ao uso de antimicrobianos, mediante imposições legais, aliadas à maior conscientização quanto à necessidade de garantir produtos saudáveis ao consumidor.

Similarmente à agricultura orgânica, a aquicultura orgânica tem atraído a atenção devido à preocupação dos consumidores em relação à sobrepesca, à degradação ambiental, aos riscos à saúde, à sustentabilidade e às questões relacionadas ao bem-estar dos animais (Lien \& Anthony, 2007; Biao, 2008). Essa nova forma de cultivo tem um futuro promissor. Segundo a FAO (2002), estima-se que a produção orgânica aumentará 240 vezes em 2030 e, de acordo com a IFOAM (2008), esse tipo de cultivo reduz a adição de insumos e proibe o uso de fertilizantes, pesticidas, produtos farmacêuticos e aditivos alimentares. No entanto, a conversão para a aquicultura orgânica implica uma alteração complexa e significativa no sistema de cultivo (Padel, 2001).

O Brasil vem aos poucos se adaptando a esse novo panorama de produção de pescado orgânico, como aponta Boscolo et al. (2012), ao afirmar que o mercado de produtos orgânicos no Brasil encontra-se em plena extensão. No entanto, Baldi \& Lopes (2008) destacam uma certa resistência por parte dos grandes grupos empresariais, que, em geral, não têm demonstrado interesse por esse tipo de produção. Tal resistência dificulta a expansão desse modo de cultivo sustentável, o que nos leva a prever que a sua adoção nos cultivos brasileiros irá demorar, a não ser que haja uma mudança de visão por parte desses empreendedores. Tal mudança pode ser feita ao serem apresentados, de modo objetivo, os resultados positivos que a produção orgânica apresenta, principalmente no que se refere à lucratividade, uma vez que o valor final do produto é diferenciado daquele advindo do cultivo tradicional, além de ser um produto mais natural, e esse tipo de produto vem sendo bastante procurado atualmente pelos consumidores.

Grande parte das estratégias propostas para mitigar os impactos promovidos pela carcinicultura prevê a implementação de processos caros, os quais restringem sua aplicação a empreendimentos de grande porte. Cabe lembrar que os custos dessas estratégias são adicionais aos custos para o cumprimento das normas ambientais (Jackson et al., 2003). Adicionalmente, o fato de muitas das atividades de carcinicultura permanecerem na ilegalidade, conforme previamente mencionado, compromete as chances de implementação de estratégias visando à conservação das áreas de cultivo e à preservação da qualidade do ambiente e das populações tradicionais de ambientes costeiros.

A utilização das tecnologias desenvolvidas a partir de pesquisas para o controle e/ou prevenção dos impactos por si só não resolve os problemas existentes na carcinicultura; é necessário que essas tecnologias sejam empregadas em conjunto com boas práticas de manejo. Paul \& Vogl (2011) corroboram com essa ideia ao afirmarem que práticas melhores são necessárias a fim de estabelecer uma aquicultura sustentável e, consequentemente, fazendas bem administradas, que geram menos impactos. Biao \& Kaijin (2007) acrescentam que a sustentabilidade almejada depende de muitos fatores, entre os quais se destacam as políticas e os regulamentos globais, a seleção de espécies, a tecnologia apropriada e o apoio adequado do governo.

Dessa forma, a busca pelo desenvolvimento sustentável desse setor produtivo remete-se ao uso de ferramentas, tais como os sistemas de gestão costeira ambiental, e à busca por uma produção mais limpa (Iles, 2007), incluindo, também, a adequada disposição dos resíduos sólidos ou líquidos contaminados (e.g. remoção dos contaminantes), aspecto esse essencial para a sustentabilidade da aquicultura (Henry-Silva \& Camargo, 2008). Somente o manejo da fazenda não é suficiente para a prática de um cultivo sustentável, é necessária uma atenção especial aos tanques de cultivo, que são os verdadeiros atores dentro desse cenário, cujo bom desempenho interfere diretamente no pleno funcionamento do cultivo. Dessa forma, a sustentabilidade dos viveiros se embasa na sua capacidade de metabolizar a carga orgânica antes que atinja o ponto de deterioração, que pode afetar o desenvolvimento e o crescimento de camarões e peixes (Avnimelech et. al., 2004). Colocando em prática o que foi sugerido acima, o funcionamento sustentável como um todo da fazenda fica garantido.

Devido à inter-dependência da relação qualidade ambiental e aquicultura (Biao \& Kaijin, 2007), é necessário que a carcinicultura tenha seu crescimento atrelado a práticas que reduzam e/ou minimizem os impactos negativos da atividade. Além disso, é 
necessário o estímulo ao fomento da aquicultura, levando em consideração os aspectos socioculturais, econômicos, tecnológicos e ambientais, bem como a redução dos períodos de produção (Camargo \& Pouey, 2005).

\section{Considerações finais}

A carcinicultura é uma atividade rentável que pode ser uma alternativa importante para suprir a carência protéica mundial, porém está frequentemente associada a impactos ambientais e socioeconômicos. No Brasil, essa atividade desenvolveu-se bastante, e, atualmente, existem tecnologias que podem ser aplicadas em todas as etapas de produção, minimizando os potenciais impactos negativos ao mesmo tempo em que promovem um aumento na produtividade. Além disso, leis foram elaboradas com o intuito de controlar a implantação, assim como as demais etapas do cultivo, com inúmeras diretrizes que visam tanto à produtividade como à preservação ambiental. Entretanto, a ilegalidade, a falta de fiscalização e a busca por lucro imediato potencialmente causam a não utilização de tecnologias apropriadas e uma menor responsabilidade socioambiental.

\section{Referências Bibliográficas}

ABCC (2004) - Código de Conduta e de Boas Práticas de Manejo para uma Carcinicultura Ambientalmente Sustentável e Socialmente Responsável. 2 ed., 18p., ABCC - Associação Brasileira de Criadores de Camarão, Recife, PE, Brasil. Disponível em http://www2.ufersa.edu.br/portal/view/uploads/ setores/234/arquivos/ABCC - BPM Fazendas.pdf

Abreu, M.C.S. de.; Mattos, P. de.; Lima, P.E.S.; Padula, A.D. (2011) Shrimp farming in coastal Brazil: Reasons for market failure and sustainability challenges. Ocean \& Coastal Management, 54(9):658667. DOI: 10.1016/j.ocecoaman.2011.06.012

Ahn, P.T.; Kroeze, C.; Bush, S.R.; Mol, A.P.J. (2010) - Water pollution intensive brackish shrimp in south-east Vietnam: Causes and options for control. Agricultural Water Management, 97(6):872-882. DOI: 10.1016/j.agwat.2010.01.018

Alam, S.M.N.; Lin, C.K.; Yakupitiyage, A.; Demaine, H.; Phillips, M.J. (2005) - Compliance of Bangladesh shrimp culture with FAO code of conduct for responsible fisheries: a development challenge. Ocean \& Coastal Management, 48(2):177-188. DOI: 10.1016/j.ocecoaman.2005.01.001

Alonso-Rodriguez, R.; Páez-Osuna, F. (2003) - Nutrients, phytoplankton and harmful algal blooms in shrimp ponds: a review with special reference to the situation in the Gulf of California. Aquaculture, 219(1-4):317-336. DOI: 10.1016/ S0044-8486(02)00509-4

Araripe, H.G.A.; Lopes, J.P.; Bastos, M.E.G. (2006) - Aspectos do licenciamento ambiental da carcinicultura na APA do delta do Parnaíba. Ambiente \& Sociedade (ISSN: 1809-4422), 9(2):143173, São Paulo, SP, Brasil. Disponível em http://www.scielo.br/ pdf/asoc/v9n2/v9n2a08.pdf

Avnimelech, Y; Ritvo, G.; Kochva, M. (2004) - Evaluating the active redox and organic fractions in pond bottom soils: EOM, easily oxidized material. Aquaculture, 233(1- 4):283-292. DOI: 10.1016/j.aquaculture.2003.10.039

Azevêdo, V.C.R. (2005) - Carcinicultura: parâmetros integrativos como instrumentos de prevenção de impactos. $160 \mathrm{p}$.,
Esses fatores somados contribuem para que a carcinicultura continue a ser associada com a degradação ambiental, assim como com impactos sociais importantes.

Para que a carcinicultura continue sendo lucrativa e torne-se sustentável, faz-se necessário o investimento em pesquisa, tecnologia e inovação. Adicionalmente, é necessária uma maior interação dos órgãos reguladores e fiscalizadores com os produtores, principalmente os pequenos empreendedores, que, muitas vezes, desçonhecem os métodos e os procedimentos adequados de cultivo. A indústria da carcinicultura precisa melhorar suas práticas de manejo de forma a estabelecer o cultivo sustentável e minimizar os potenciais efeitos negativos de ordem socioeconômica e ambiental.

\section{Agradecimentos}

V. Hatje e F. Barros agradecem ao CNPq pela concessão de bolsa. L.F. Ribeiro agradece a bolsa concedida pela FAPESB. Os autores agradecem os comentários dos dois revisores anónimos.

Dissertação de Mestrado, Universidade Federal da Bahia, Salvador, BA, Brasil. Disponível em http://www.teclim.ufba.br /site/material_online/dissertacoes/dis_veronica_cristina.pdf

Badiola, M.; Mendiola, D.; Bostock, J. (2012) - Recirculating Aquaculture Systems (RAS) analysis: Main issues on management and future challenges. Aquacultural Engineering, 51:26-35. DOI: 10.1016/j.aquaeng.2012.07.004

Baldi, M.; Lopes, F. (2008) - Primar orgânica: inovação em tempos de crise. Cadernos EBAPE.BR, 6(3):1-16. DOI: 10.1590/S167939512008000300005

Balmford, A.; Bruner, A.; Cooper, P.; Costanza, R.; Farber, S.; Green, R.E. Jenkins, M.; Jefferiss, P.; Jessamy, V.; Madden, J.; Munro, K.; Myers, N.; Naeem, S.; Paavola, J.; Rayment, M.; Rosendo, S.; Roughgarden, J.; Trumper, H.; Turner, R.K. (2002) - Economic reasons for conserving wild nature. Science, 297(5583):950-953. DOI: 10.1126/science.1073947

Barbier, E.B. (2006) - Natural barriers to natural disasters: replanting mangroves after the tsunami. Frontiers in Ecology and the Environment, 4(3):124-131. DOI: http://dx.doi.org/ 10.1890/1540-9295(2006)004\%5b0124:NBTNDR\%5d2.0.CO;2

Barbier, E. B.; Strand, I. (1998) - Valuing mangrove fishery linkages: a case study of Campeche, Mexico. Environmental and Resource Economics,12(2):151-166. DOI: 10.1023/A: 1008248003520

Barros, S.R.R.C. de. (2006) - Estudo da partição de metais traço em uma linha d'água de um tanque de cultivo de camarão marinho do município de Santa Rita - PB. 94p., Dissertação de Mestrado, Universidade Federal da Paraíba, João Pessoa, PB, Brasil. Disponível em http://www.ppgq.quimica.ufpb.br/dissertacoes/ Dissertacao_Sara_Regina_Carneiro.pdf

Barton, M.D. (2000) Antibiotic use in animal feed and its impact on human health.Nutrition Research Reviews,13(2):279-299. DOI: 10.1079/095442200108729106

Bezerra, M.A. (2010) - A retomada da carcinicultura no Brasil: vivemos uma nova realidade econômico-financeira nas unidades 
produtoras de camarões no Nordeste Brasileiro? Panorama da Aquicultura (ISSN: 1519-114), 20(121):54-59, Laranjeiras, RJ, Brasil.

Biao, X. (2008) - The development of and prospects for organic aquaculture worldwide. Outlook on Agriculture, 37(4):255-260. DOI: $10.5367 / 000000008787167718$

Biao, X.; Kaijin, Y. (2007) - Shrimp farming in China: operating characteristics, environmental impact and perspectives. Ocean Coastal Management, 50(7):538-550. DOI: 10.1016/j. ocecoaman.2007.02.006

Boscolo, W.R.; Feiden, A.; Neu, D.H.; Dieterich, F. (2012) Sistema orgânico de produção de pescado de água doce. Revista Brasileira de Saúde e Produção Animal (ISSN: 1519- 9940), 13(2):578-590. Disponível em http://revistas.ufba.br/index.php/ $\mathrm{rbspa} /$ article/view/2541/1351

Bostock, J.; McAndrew, B; Richards, R.; Jauncey, K.; Telfer, T.; Lorenzen, K.; Little, D.; Ross, L.; Handisyde, N.; Gatward, I; Comer, R. (2010) - Aquaculture: Global status and trends. Philosophical Transactions of the Royal Society Biological. 365(1554):2897-2912. DOI: 10.1098/rstb.2010.0170

Brummett, R. E. (2003) - Aquaculture and Society in the New Millennium. World Aquaculture Magazine (ISSN: 1041-5602), 34(1):51-59, World Aquaculture Society, Baton Rouge, LA, U.S.A., Disponível em https://www.was.org/magazine/ ArticleContent.aspx? $\mathrm{Id}=111$

Burford, M.A.; Thompson, P.J.; McIntosh, R.P.; Bauman, R.H.; Pearson, D.C. (2003) - Nutrient and microbial dynamics in high-intensity, zero-exchange shrimp ponds in Belize. Aquaculture. 219(1-4):393-411. DOI: 10.1016/S00448486(02)00575-6

Camargo, S.G.O.; Pouey, J.L.O.F. (2005) - Aquicultura - um mercado em expansão. Revista Brasileira Agrociência (ISSN0104-8996), 11(4):393-396, Pelotas, RS, Brasil. Disponível em http://www.ufpel.tche.br/faem/agrociencia/v11n4 /artigo01.pdf

Carvalho, R. (2005) - Camarões marinhos: gestão de qualidade e rastreabilidade na fazenda. Associação Brasileira dos Criadores de Camarão. 1 ed., 96p., ABCC - Associação Brasileira de Criadores de Camarão, publicação eletrônica, Recife, PE, Brasil. Disponível em http://www.ongprojetocidam. org.br/arquivos_upload/CamaroesMarinhosGestaodeQualidadeGrande.pdf

Castro, A.A., Pagani, G.D. (2004) - Secagem e composição química da cabeça de camarão (Litopenaeus vannamei Boone) a diferentes temperaturas. Revista Brasileira de Produtos Agroindustriais (ISSN 1517-8595), 6(2):123- 129. Campina Grande, PB, Brasil. Disponível em http://www.deag.ufcg. edu.br/rbpa/rev62/Art623.pdf

Cavalcanti, L.E. (2012) - Aspectos geoambientais da carcinicultura no Rio Grande do Norte e seus desdobramentos legais: a implementação da licença ambiental em defesa do meio ambiente. Revista dos Estudantes de Direito da UnB (ISSN 2177-6458), 10-E (Especial Eletrônica):71-88, Brasília, DF, Brasil. Disponível em http://periodicos.bce.unb.br/index.php/ redunb/article/view/7121/5614

Chen, J.; Lin, C. (2001) - Toxicity of copper sulfate for survival, growth, molting and feeding of juveniles of the tiger shrimp Penaeus monodon. Aquaculture, 192(1):55- 65. DOI: 10.1016/S0044-8486(00)00442-7

Constanzo, S.D.; O’Donohue, M.J.; Dennison, W.C.(2004) Assessing the influence and distribution of shrimp pond effluent in a tidal mangrove creek in northeast Australia. Marine Pollution Bulletin, 48(5-6):514-525. DOI: 10.1016/j.marpolbul. 2003.09.006

Costa, R.B. (2009) - Importância Econômica, Social e Impactos Ambientais da Carcinicultura: Estudo de Caso em Fazenda do
Município de Acaraú, Ceará. 83p., Monografia de Graduação, Universidade Federal do Ceará, Fortaleza, CE, Brasil. Disponível em http://www.lemos.pro.br/admin/artcientifico/ 12472530284a579224c6f0c.pdf

Costa, W.M. (2004) - Efeito da proteína vegetal na qualidade de água dos efluentes da carcinicultura. 69p., Dissertação de Mestrado, Universidade Federal de Pernambuco, Recife, PE, Brasil. Disponível em http://www.pgpa.ufrpe.br/Trabalhos/ 2004/T2004wmc.pdf

Crab, R.; Avnimelech, Y.; Defoirdt, T.;Bossier, P.; Verstraete, W. (2007) - Nitrogen removal techniques in aquaculture for a sustainable production. Aquaculture, 270(1-4):1-14. DOI: 10.1016/j.aquaculture.2007.05.006

Ellison, A.M. (2008) - Managing mangroves with benthic biodiversity in mind: moving beyond roving banditry. Journal of Sea Research, 59(1-2):2-15. DOI: 10.1016/j.seares. 2007.05.003

FAO (1995) - Code of conduct for responsible fisheries. 49p., FAO - Food and Agriculture Organization of the United Nations, Roma, Itália. ISBN: 9251038345. Disponível em $\mathrm{http}: / / \mathrm{ftp}$.fao.org/docrep/fao/005/v9878e/v9878e00.pdf

FAO (2002) - The state of food insecurity in the world. 4th ed., 134 p., FAO - Food and Agriculture Organization of the United Nations, Roma, Itália. ISBN: 9251048150. Disponível em: http://www.fao.org/docrep/005/y7352e/y7352e00.htm

FAO (2006) - State of World Aquaculture. Inland Water Resources and Aquaculture Service. 134p., FAO - Food and Agriculture Organization of the United Nations, Roma, Itália. ISBN: 97892-5-105631-8.Disponível em: http://fao.org/docrep/fao/ 009/a0874e/a0874e00.pdf

Figueirêdo, M.C.B. de.; Araújo, L.F.P.; Rosa, M.F.; Morais, L.F.S.de.; Paulino, W.D.;Gomes, R.B. (2006) - Impactos ambientais da carcinicultura de águas interiores. Revista Engenharia Sanitária e Ambiental (ISSN 1809-4457), 11(3):231-240, Rio de Janeiro, RJ, Brasil. Disponível em http://www.scielo.br/pdf/esa/v11n3/a06v11n3.pdf

Flaherty, M.; Karnjanakesorn, C. (1995) - Marine shrimp aquaculture and natural resource degradation in Thailand. Environmental Management, 19(1):27-37. DOI: 10.1007/BF02472001

Gál, D.; Szabó, P.; Pekár, F.; Váradi, L. (2003) - Experiments on the nutrient removal and retention of a pond recirculation system. Hydrobiologia, 506-509(1):767- 772. DOI: 10.1023/B:HYDR.0000008589.46810.af

Garcia, C. (2012) - Ibama participa de operação de combate à carcinicultura irregular. In: Notícias Ambientais, portal eletrônico do IBAMA - Instituto Brasileiro do Meio Ambiente e dos Recursos Naturais Renováveis. Brasília, DF, Brasil. Disponível em http://www.ibama.gov.br/publicadas/ibamaparticipa-de-operacao-de-combate-acarcinicultura-irregular

Gosavi, K.; Sammut, J.; Gifford, S.; Jankowski, J. (2004) Macroalgal biomonitores of trace metal contamination in acid sulfate soil aquaculture ponds. Science of the Total Environment (ISSN 0048-9697), 324(1-3):25-39. DOI: 10.1016/j.scitotenv. 2003.11.002

Gräslund, S.; Bengtsson, B-E.(2001) - Chemicals and biological products used in south-east Asian shrimp farming, and their potential impact on the environment - a review. The Science of the Total Environment, 280(1-3):93-131. DOI: 10.1016/S00489697(01)00818-X

Gutierrez-Wing, M.T.; Malone, R.F. (2006) - Biological filters in aquaculture: trends and research directions for freshwater and marine applications. Aquacultural Engineering, 34(3):163-171. DOI: $10.1016 /$ j.aquaeng.2005.08.003

Hadlic, G.M.; Ucha, J.M. (2009) - Apicuns: aspectos gerais, evolução recente e mudanças climáticas globais. Revista 
Brasileira de Geomorfologia (ISSN: 2236-5664),10(2):13-20, Porto Alegre, RS, Brasil. Disponível em http://www.lsie.unb.br/ rbg/index.php/rbg/article/download/126/120

Henry-Silva, G.G.; Camargo, A.F.M. (2008) - Impacto das atividades de aqüicultura e sistemas de tratamento de efluentes com macrófitas aquáticas - relato de caso. Boletim do Instituto de Pesca (ISSN 1678-2305), 34(1):163-173, São Paulo, SP, Brasil. Disponível em ftp://ftp.sp.gov.br/ftppesca/34_1_163173.pdf

Hossain, S.; Khan, Y.S.A. (2001) - Trace metals in Penaeid shrimp and Spiny lobster from the Bay of Bengal. Science Asia (ISSN 1513-1874), 27: 165-168, Bangkok, Thailand. Disponível em http://www.scienceasia.org/2001.27.n3/v27_165_168.pdf

Iles, A. (2007) - Making the seafood industry more sustainable: creating production chain transparency and accountability. Journal of Cleaner Production,15(6):577-589. DOI: 10.1016/j.jclepro.2006.06.001

IBAMA (2005) - Diagnóstico da Atividade de Carcinicultura no Estado do Ceará. IBAMA - Instituto Brasileiro do Meio Ambiente e dos Recursos Naturais Renováveis, Fortaleza, CE, Brasil. Disponível em http://sispub.oktiva.com.br/oktiva. net/anexo/13454

IMA (2009) - Mapeamento de empreendimentos de carcinicultura no litoral baiano - Julho de 2007 a Junho de 2009. Relatório Técnico. IMA - Instituto do Meio Ambiente, Salvador, BA, Brasil

IFOAM (s/d) - The Principles of Organic Agriculture. International Federation of Organic Agriculture Movements, Bonn, Germany. In: http://infohub.ifoam.org/en/what-organic/principles-organicagriculture

Jackson, C.; Preston, N.; Burford, S.A.; Thompson, P.J. (2003) Managing the development of sustainable shrimp farming in Australia: the role of sedimentation ponds in treatment of farm discharge water. Aquaculture, 226(1-4):23-34. DOI: 10.1016/S0044-8486(03)00464-2

Jahan, H. (2013) - Towards sustainable development of shrimp farming in Bangladesh: The economy versus the environment. 167p., Tese de Doutorado. Universidade de Sidnei. Austrália. Disponível em http://ses.library.usyd.edu.au//bitstream/ 2123/9492/3/Amended thesis_Hasneen Jahan.pdf

Jakob, G.S.; Pruder, G.D.; Wang, J. (1993) - Growth trial with the American oyster Crassostrea virginica using shrimppond water as feed. Journal of World Aquaculture Society, 24(3):344 - 351. DOI: $10.1111 / j .1749-7345.1993 . t b 00166 . x$

Jones, A.B.; O’Donohue, M.J.; Udy, J.; Dennison, W.C. (2001) Assessing ecological impacts of shrimp and sewage effluent: Biological indicators with standard water quality analyses. Estuarine, Coastal and Shelf Science, 52(1):91-109. DOI: 10.1006/ecss.2000.0729

Kubitza, F. (2006) - Sistemas de Recirculação:Sistemas fechados com tratamento e reuso da água. Panorama da Aqüicultura (ISSN 1519-1141), 16(95):15-22, Laranjeiras, RJ, Brasil. Disponível em http://www.acquaimagem.com.br/aquagenetica/ site/wp-content/principios sistema recirculacao.pdf

Kungvankij, P.; Chua, T.E.; Pudadera, B.J.; Tiro, L.B.; Corre, G.; Potestas, I; O., Borlongan Alava, E.; Taleon, G.A.; Paw, J.N. (1989) - Shrimp Culture: Pond Deign, Operation and Management. 68p., NACA Training Manual Series n.2, FAO - Food and Agriculture Organization of the United Nations, Southeast Asian Fisheries Development Center (SEAFDEC), Bangkok, Thailand. Disponível em http://www.fao.org/docrep/field/003/ac210e/ac210e00.HTM

Lacerda, L.D.; Santos, J.A.; Madrid, R.M. (2006) - Copper emission factors from intensive shrimp aquaculture. Marine Pollution Bulletin. 52(12):1823-1826. DOI: 10.1590/S151969842009000400012
Lacerda, L.D; Santos, J.A.; Lopes, D.V. (2009) - Fate of copper in intensive shrimp farms: bioaccumulation and deposition in pond sediments. Brazilian Journal of Biology, 69(3):851-858.DOI: 10.1590/S1519-69842009000400012

Lacerda, L.D.; Soares, T.M.; Costa, B.G.B.; Godoy, M.D.P. (2011) Mercury emission factors from intensive shrimp aquaculture and their relative importance to the Jaguaribe River Estuary, NE Brazil. Bulletin of environmental contamination and toxicology, 87:657-661. DOI: 10.1007/s00128-011-0399-4

Latorre, S. (2012) - Territorialities of Power in the Ecuadorian Coast: The Politics of an Environmentally Dispossessed Group. 30p., desiguALdades.net - Research Network on Interdependent Inequalities in Latin America, Working Paper Series, No. 23, Berlin, Germany. Disponível em http://edocs.fuberlin.de/docs/servlets/MCRFileNodeServlet/FUDOCS_derivat e 000000001950/WP_23_Latorre_Online.sonid $=03048 \mathrm{BC} 1 \mathrm{E} 84$ 13BE31AFD2270C0A5CD25?hosts=

Le, T.X.; Munekage, Y. (2004) - Residues of selected antibiotics in water and mud from shrimp ponds in mangrove areas in Viet Nam. Marine Pollution Bulletin, 49(11-12):922- 929. DOI: 10.1016/j.marpolbul.2004.06.016

Lien, M.; Anthony, R. (2007) - Ethics and the politics of food. Journal of Agricultural and Environmental Ethics, 20(5):413417. DOI: $10.1007 / \mathrm{s} 10806-007-9049-6$

Lin, Y-F.; Jing, S-R.; Lee, D-Y.; Wang, T-W.(2002) - Nutrient removal from aquaculture wastewater using a constructed wetlands system. Aquaculture, 209(1-4):169-184. DOI: 10.1016/S0044-8486(01)00801-8

Lynch, J.M.; Moffat A.J. (2005) - Bioremediation - prospects for the future application of innovative applied biological research. Annals of Applied Biology, 146(2):217-221.DOI: 10.1111/j.1744-7348.2005.040115.x

Mamani, M.C.V. (2007) - Desenvolvimento e validação de métodos para a determinação de antimicrobianos em leite e fármacos usando a cromatografia líquida de alta eficiência e eletroforese capilar. 208p., Dissertação de Doutorado, Universidade Estadual de Campinas, Campinas, SP, Brasil. Disponível em http://biq.iqm.unicamp.br/arquivos/teses/vtls000416794.pdf

Martins, C.I.M.; Eding, E.H.; Verdegem, M.C.J.; Heinsbroek, L.T.N.; Schneider, O.; Blancheton, J.P.; Roque d'Orbcastel, E.; Verretha, J.A.J. (2010) - New developments in recirculating aquaculture systems in Europe: A perspective on environmental sustainability. Aquacultural Engineering, 43(3):83-93. DOI: 10.1016/j.aquaeng.2010.09.002

Mcintosh, B.J.; Samocha, T.M.; Jones, E.R.; Lawrence, A.L.; Mckee, D.A. (2000) - The effect of a commercial bacterial supplement on the high-density culturing of Litopenaeus vanammei with low-protein diet on outdoor tank system and no water exchange. Aquacultural Engineering, 21(3):215-227. DOI: $10.1016 / \mathrm{S} 0144-8609(99) 00030-8$

Meirelles, A.J.A. (2005) - Riscos sócio-ambientais ao longo da zona costeira. Simpósio Riscos Naturais e Antropicos na Zona Costeira, Fortaleza, CE, Brasil. Disponível em http://www.sbpcnet.org.br/livro/57ra/programas/CONF_SIMP/t extos/antoniomeireles.htm

Meireles, A.J.A.; Queiroz, L. (2010) - A monocultura do camarão: danos socioambientais à base da vida comunitária tradicional no litoral do Nordeste brasileiro. In:Andréa Zhouri \& Klemens Laschefski (org.), Desenvolvimento e Conflitos Ambientais, pp.224-249, Editora UFMG (Universidade Federal de Minas Gerais), Belo Horizonte, MG, Brasil. ISBN: 978-857041749. Disponível em http://wp2.oktiva.com.br/portaldomarbd/files/ 2010/08/A-Monocultura-do-camarao-jeovah-e-Luciana.pdf

Mialhe, F; Gunnell, Y.; Mering, C. (2013) - The impacts ofshrimp farming on land use, employment and migration in Tumbes, 
northern Peru. Ocean \& Coastal Management, 73:1-12. DOI: 10.1016/j.ocecoaman.2012.12.014

Milanese, M.; Chelossi, E.; Manconi, R.; Sara, A.; Sidri, M.; Pronzato, P. (2003) - The marine sponge Chondrilla núcula (Schmidt, 1862) as an elective candidate forbio remediation in integrated aquaculture. Biomolecular Engineering, 20(4-6):363368. DOI: $10.1016 /$ S1389-0344(03)00052-2

MPA. (2011) - Boletim Estatístico da Pesca e Aquicultura.Brasil 2008-2009. 99p., MPA - Ministério da Pesca e Aquicultura Brasília, DF, Brasil. In: http://www.mpa.gov.br/images/ Docs/Publicidade/anuário da pesca completo2.pdf

Moles, P.; Bunge, J. (2002) - Shrimp Farming in Brazil: An Industry Overview. 26p., Report prepared under the World Bank, NACA, WWF and FAO Consortium Program on Shrimp Farming and the Environment. Work in Progress for Public Discussion. Disponível em: http://library.enaca.org/Shrimp/Case/Latin America/Brazil/ShrimpFarmingBrazil.pdf

Nascimento, I.A. (2007) - Manguezal e carcinicultura: o conflito da ecocompatibilidade. Revista Diálogos e Ciência (ISSN 16780493), 5(10):1-15, Salvador, BA, Brasil. Disponível em http://dialogos.ftc.br/index.php?option $=$ com_docman\&task $=$ doc download\&gid $=88 \&$ Itemid $=15$

Natori, M.M.; Sussel, F.R.; Santos, E.C.B. dos.; Previero, T. De C.; Viegas, E.M.M.; Gameiro, A.H. (2011) - Desenvolvimento da carcinicultura marinha no Brasil e no mundo: avanços tecnológicos e desafios. Informações Econômicas (ISSN01004409), 41(2):61-73, São Paulo, SP, Brasil. Disponível em ftp://ftp.sp.gov.br/ftpiea/publicacoes/ie/2011/tec6-0211.pdf

Naylor, R.L.; Goldburg, R.J.; Primavera, J.H.; Kautsky, N.; Beveridge, M.C.M.; Clay, J.; Folke, C.; Lubchenco, J.; Mooney, H.; Troell, M. (2005) - Effect of aquaculture on world fish supplies. Nature, 405:1017-1024. DOI: 10.1038/35016500

Neiland, A.E.; Soley, N.; Varley, J.B.; Whitmarsh, D.J. (2001) Shrimp aquaculture: economic perspectives for policy development. Marine Policy, 25(4):265-279. DOI: 10.1016/ S0308-597X(01)00017-3

Nóbrega, G.N.; Ferreira, T.O.; Romero, R.E.; Marques, A.G.B.; Otero, X.L. (2013) - Iron and sulfur geochemistry in semi-arid mangrove soils (Ceará, Brazil) in relation to seasonal changes and shrimp farming effluents. Environmental Monitoring and Assessment, 185(9):7393-7407. DOI: 10.1007/s10661-0133108-4

Nomen, R.; Sempere, J.; Chávez, F.; López, N.A.de.; Rovira, M-D.(2012) Measurement of pollution levels of organochlorine and organophosphorus pesticides in water, soil, sediment, and shrimp to identify possible impacts on shrimp production at Jiquilisco Bay. Environmental science and pollution research international, 19(8):3547-3555. DOI: 10.1007/s11356-012-0916-y

Nunes, A.J.P.; Gesteira, T.C.V.; Goddard, S. (1997) - Food consumption and assimilation by the Southern brown shrimp Penaeus subtilis under semi-intensive culture in NE Brazil. Aquaculture, 149(1-2):121-136. DOI: 10.1016/S0044-8486 (96)01433-0

Nunes, A.J.P. (2001) - Alimentação para camarões marinhos (Parte II). Panorama da Aquicultura (ISSN 1519-114),11(63):13-23. Laranjeiras, RJ, Brasil. Disponível em http://www.panorama daaquicultura.com.br/paginas/revistas/63/manualcamaraoParteII .asp

Oliveira, R.C.de. (2009) - O panorama da aquicultura no Brasil: a prática com foco na sustentabilidade. Revista Intertox de Toxicologia, Risco Ambiental e Sociedade (ISSN 1984-3577), 2(1):71-89. São Paulo, SP, Brasil. Disponível em http://intertox. com.br/phocadownload/Revinter/v2n1/rev-v02-n01-05.pdf

Padel, S. (2001) - Conversion to organic farming: a typical example of the diffusion of an innovation? Sociologia Ruralis, 41(1):40-

\section{DOI: $10.1111 / 1467-9523.00169$}

Páez-Osuna, F. (2001) - The environmental impact of shrimp aquaculture a global perspective. Environmental pollution, 112(2):229-231. DOI: 10.1016/S0269-7491(00)00111-1

Paéz-Osuna, F.; Flores-Verdugo, F.; Lyle-Fritch, L.P.; AlonsoRodríguez, R.; Roque, A.; Ruiz-Fernández, A.C. (2003) Shrimp aquaculture development and the environment in the Gulf of California ecoregion. Marine Pollution Bulletin. 46(7):806-815. DOI: 10.1016/S0025-326X(03)00107-3

Paul, B.G.; Vogl, C.R. (2011) - Impacts of shrimp in Bangladesh: Challenges and alternatives. Review. Ocean \& Coastal Management, 54(3):201-211. DOI: 10.1016/j.ocecoaman.2010.12.001

Piedrahita, R.H. (2003) - Reducing the potential environmental impact of tank aquaculture effluents through intensification and recirculation. Aquaculture, 226(1-4):35-44. DOI: 10.1016/ S0044-8486(03)00465-4

Pillay, T.V.R.; Kutty, M.N. (2005) - Aquaculture: Principles and practices. 640p., Wiley-Blackwell Publishing, Oxford, U.K. ISBN: 1405105321.

Poersch, L.H.S. (2004) - Aquacultura no estuário da Lagoa dos Patos e sua influência sobre o meio ambiente. 146p., Tese Doutorado, Fundação Universidade Rio Grande Rio Grande, Rio Grande do Sul, Brasil. Não Publicado.

Pontes, C.S.; Arruda, M.F. (2005) - Artificial food access and digestive tract filling of juvenil marine shrimp Litopenaeus vannamei (Boone) (Crustacea, Decapoda, Penaeidae) during light and dark phases in 24-hour period. Revista Brasileira de Zoologia, 22(4):1039-1043. DOI: 10.1590/S0101-8175200 5000400032

Primavera, J.H. (1997) - Socio-economic impacts of shrimp culture. Aquaculture Research. 28(10):815-827. DOI: 10.1046/j.13652109.1997.00946.x

Primavera, J.H. (2006) - Overcoming the impacts of aquaculture on the coastal zone. Ocean \& Coastal Management, 49(9-10):531545. DOI: 10.1016/j.ocecoaman.2006.06.018

Pullin, R.S.V.; Rosenthal, H.; Maclean, J.J. (Eds.) (1992) Environment and aquaculture in developing countries. Conference on Environment and Aquaculture in Developing Countries, Contribution $n^{\circ}$ 941, 359p., International Center for Living Aquatic Resources Management, Manila, Philippines / Deutsche Gesellschaft für Technische Zusammenarbeit, Frankfurt, Germany. ISBN: 971-8709-05. Disponível em http://www.worldfishcenter.org/libinfo/Pdf/Pub CP6 31.pdf

Quaglia, L.J.C. (1993) - Estudo da qualidade da água do canal de Taperoá (Valença-Ba): Implicações na carciniculturamarinha. 118p., Tese de Mestrado. Universidade Federal da Bahia. Salvador, Bahia, Brasil. Não publicado.

Queiroz, L.; Rossi, S.; Meireles, J.; Coelho, C. (2013) - Shrimp aquaculture in the federal state of Ceará, 1970 - 2012: Trends after mangrove forest privatization in Brazil. Ocean \& Coastal Management, 73:54-62. DOI: 10.1016/j.ocecoaman.2012.11.009

Read, P.; Fernandes, T. (2003) - Management of environmental impacts of marine aquaculture in Europe. Aquaculture, 226(14):139-163. DOI: 10.1016/S0044-8486(03)00474-5

Rocha, I.P.; Rodrigues, J.; Amorim, L.A. (2004) - Carcinicultura Brasileira em 2003. Revista da Associação Brasileira de Criadores de Camarão (ABCC), 6(1):30-36, Natal, RN, Brasil. Disponível em http://issuu.com/tfds1/docs/revista_abcc_mar o_2004

Santos, P.N. (2009) - Validação de metodologias para determinação de antimicrobianos em pescado por cromatografia líquida de alta eficiência. 84p., Dissertação de Mestrado. Universidade Federal Rural de Pernambuco, Recife, PE, Brasil. Disponível em http://200.17.137.108/tde_busca/arquivo.php?codArquivo=759

Sahu, B. C.; Adhikari, S.; Dey, L. (2013) - Carbon, nitrogen and 
phosphorus budget in shrimp(Penaeus monodon) culture ponds in eastern India. Aquaculture International, 21(2):453 - 466. DOI: $10.1007 / \mathrm{s} 10499-012-9573-\mathrm{x}$

Sammut, J.; White, I.; Melville, M. D. (1996) - Acidification of an estuarine tributary in eastern Australia due to drainage of acid sulfate soils. Marine and Freshwater Research, 47(5):669-684. DOI: 10.1071/MF9960669

Smith, D. M.; Burfod, M. A.; Tabrett, S. J.; Irvin, S. J.; Ward, L. (2002) - The effect of feeding frequency on water quality and growth of the black tiger shrimp (Penaeus monodon). Aquaculture, 207(1-2):125-136. DOI: 10.1016/S00448486(01)00757-8.

Sotomayor, M.A.; Balcázar, L.J. (2003) - Inhibición de vibrios patógenos de camarón por mezclas de cepas probióticas. Revista AquaTic(ISSN 1578-4541), 9:9- 15, Madrid, Espanha. Disponível em: http://www.revistaaquatic.com/aquatic/ pdf/19_2.pdf

Souza, M.C.M.B.N. (2013) - Impacto de efluentes de carciniculturas na qualidade de água e sedimento: Baía de Todos os Santos, Bahia, Brasil. 48p., Dissertação de Mestrado, Universidade Federal da Bahia, Salvador, BA, Brasil. Não publicado.

Summerfelt, S.T.; Sharrer, M.J.; Tsukuda, S.M.; Gearheart, M. (2009) - Process requirements for achieving full-flow disinfection of recirculating water using ozonationand UV irradiation. Aquaculture Engineering, 40(1):17-27. DOI: 10.1016/j.aquaeng.2008.10.002

Tal, Y.; Schreier, H.J.; Sowers, K.R.; Stubblefield, J.D.; Place, A.R.; Zohar, Y. (2009) - Environmentally sustainable land-based marine aquaculture. Aquaculture, 286(1- 2):28-35. DOI:

\section{Legislação referida}

Brasil:

Resolução CONAMA $n^{\circ} 312$, de 10 de outubro de 2002. Dispõe sobre o licenciamento ambiental dos empreendimentos de carcinicultura na zona costeira. Ministério do Meio Ambiente, Conselho Nacional do Meio Ambiente, Brasília, DF, Brasil. Publicada no DOU de 18/10/2002. Disponível em http://www.mma.gov.br/port/conama/res/res02/res31202.html

Decreto $n^{\circ} 24.548$ de 3 de julho 1934. Aprova o Regulamento do Serviço de Defesa Sanitária Animal. Coleção de leis do Brasil de 1934. Presidência da República, Casa Civil, Brasília, DF, Brasil. Disponível em http://www.planalto.gov.br/ ccivil_03/decreto/1930-1949/D24548.htm

Decreto-Lei $N^{o} 986$ de 21 de outubro de1969. Institui normas básicas sobre alimentos. Presidência da República, Casa Civil, Brasília, DF, Brasil. Publicado no D.O.U. de 21.10.1969. Disponível em http://www.planalto.gov.br/ccivil_03/DecretoLei/Del0986.htm

Lei $n^{\circ} 12.651$, de 25 de maio de 2012. Dispõe sobre a proteção da vegetação nativa. Presidência da República, Casa Civil, Brasília, DF, Brasil. Publicada no DOU de28.5.2012. Disponível em http://www.planalto.gov.br/ccivil_03/_ato20112014/2012/lei/112651.htm

\section{Chile:}

Ley 19300/94. Ley sobre bases generales del medio ambiente. Ministerio Secretaría General de la Presidência, Santiago, Chile. Disponível em http://www.leychile.cl/Navegar?idNorma=30667

Decreto $N^{\circ} 90$. Establece norma de emisión para la regulación de contaminantes asociados a las descargas de residuos líquidos a aguas marinas y continentales superficiales. Fecha Promulgación: 30-MAY-2000.Ministerio Secretaría General de la

\subsection{6/j.aquaculture.2008.08.043}

Thompson, F.L.; Abreu, P.C.; Wasielesky, W. (2002) - Importance of biofilmfor water quality and nourishment in intensive shrimp culture. Aquaculture, 203(3-4):263- 278. DOI: 10.1016/S00448486(01)00642-1

Toro, C.R. (2005) - Uso de bactérias lácticas probióticas na alimentação de camarões Litopenaeus vannamei como inibidoras de microrganismos patogênicos e estimulantes do sistema imune. $173 \mathrm{p}$., Tese de Doutorado,Universidade Federal do Paraná, Curitiba, PR, Brasil. Disponível em http://www.bioprocessos.net.br/docs/Tese-CRISTINATORO2005.pdf

Verdegem, M.C.J.; Bosma, R.H.; Verreth, J.A.J. (2006) - Reducing water use for animal production through aquaculture. International Journal of Water Resources Development, 22(1):101-113. DOI: 10.1080/07900620500405544

Visuthismajarn, P.; Vitayavirasuk, B.;Leeraphante, N.; Kietpawpan, M. (2005) - Ecological risk assessment of abandoned shrimp ponds in Southern Thailand. Environmental Monitoring and Assessment, 104(1-3):409- 418. DOI: 10.1007/s10661-0051681-X

Wu, J-P.; Chen, H-C.(2005) - Effects of Cadmium and Zinco on the growth, food, consumption, and nutritional conditions of the white shrimp Litopeneaus vannamei (Boone). Bulletin of Environmental Contamination and Toxicology, 74(2):234-241. DOI:10.1007/s00128-004-0575-x

Yamprayoon, J.; Sukhumparnich, K. (2010) - Thaiaquaculture: achieving quality and safety through management and sustainability. Journal of the World Aquaculture Society, 41(2):274-280. DOI: 10.1111/j.1749-7345.2010.00355.x

Presidencia, Santiago, Chile. Disponível em http://www.leychile.cl/Navegar?idNorma=182637

Decreto $n^{\circ} 1$. Reglamento para el Control de la Contaminación Acuática. Fecha Promulgación: 06-ENE-1992.

Presidencia da Republica, Ministerio de Defensa Nacional, Subsecretaria de Marina. Santiago, Chile. Disponível em http://www.leychile.cl/Navegar?idNorma $=7232$

China:

Marine Environment Protection Law 1982. The Standing Committee of the National People's Congress Order $n^{\circ} 9$. Ministry of Environmental Protection the People's Republic of China. China. Disponível em http://english.mep.gov.cn/ Policies_Regulations/laws/environmental_laws/200710/t200710 09_109912.htm

Law on the Prevention and Control of Water Pollution 1984/1996. Order of the President of the People's Republic of China No.87, adopted on May 11, 1984; amended on May 15, 1996,Ministry of Environmental Protection.China. Disponível em http://www. china.org.cn/english/environment/34325.htm

Rules for implementation of the the prevention and control of water pollution (Decree No.1).Promulgated on July 12, 1989.Consolidation on March 20, 2000.State Bureau of the Environment Protection.Pequim, China. Disponível em http://www.asianlii.org/cn/legis/cen/laws/rfiottpacowp777

\section{Equador:}

Decreto $\mathrm{N}^{\mathrm{0}}$ 1.732.Modifica el Reglamento general a la Ley de Pesca y Desarrollo Pesquero (25 May 2009). Registro Oficial No. 606 
- Viernes 05 de Junio de 2009, Presidente Constitucional de La Republica Del Ecuador. Disponível em http://faolex.fao.org/ docs/texts/ecu92570.doc

\section{México:}

Reglamento de la Ley General del Equilibrio Ecológico y la Protección al Ambiente en Materia de Evaluación del Impacto Ambiental. 19p., Nuevo Reglamento publicado en el Diario Oficial de la Federación el 30 de mayo de 2000,Secretaría de Medio Ambiente y Recursos Naturales, Ciudad de México, México. Disponível em http://www.ibiologia.unam.mx/ reserva/leyes/pdf/4.pdf 